\title{
EL ARCHIVO DE RAMÓN SIJÉ
}

\author{
Aitor L. LARRABIDE \\ Fundación Cultural Miguel Hernández
}

\section{INTRODUCCIÓN}

En el verano de 2004 la heredera de Ramón Sijé, doña Carmen Saldaña, cedió a la Fundación Cultural Miguel Hernández, con sede en Orihuela, la totalidad del legado que perteneció al ensayista oriolano. Después de un primer esfuerzo dedicado a la ordenación de todo el material, Delia Martínez Torres y yo, gracias a unas ayudas recibidas del Ministerio de Cultura, iniciamos en junio de 2006 el escaneado del mismo y su estudio. Después ha venido su catalogación y su posterior acceso a los investigadores en la Sala Hernandiana de la Biblioteca Pública del Estado en Orihuela "Fernando de Loazes", gracias al convenio establecido con la Fundación Cultural Miguel Hernández. De este modo, un legendario archivo como el de Ramón Sijé es ya accesible a todas aquellas personas interesadas.

Hasta la fecha, pocos investigadores consultaron este archivo, total o parcialmente. Recordamos a Francisco Martínez Marín, José Muñoz Garrigós, Ramón Pérez Álvarez, José Antonio Sáez Fernández o Antonio Luis Galiano 
Pérez. El generoso José Torres López nunca negó a nadie la consulta precisa, y es de justicia decirlo alto y claro aquí.

Las vicisitudes del archivo son bien conocidas. A las muertes de José Marín Gutiérrez en 1935 y de su hermano Justino en 1946, Mari-Lola, única familiar próxima, hereda los legados de ambos, especialmente el del primero. Al morir ésta en 1964, su viudo, el citado José Torres López, casado en segundas nupcias con doña Carmen Saldaña, se encarga de su custodia y conservación, hasta su fallecimiento. Una grave inundación en los años cincuenta provoca la pérdida o grave deterioro de algunos documentos, además de otras circunstancias menos decorosas.

Ese carácter de archivo casi desconocido hacía precisa una rápida intervención. Ya en 1995 pude conocerlo parcialmente, pero mi principal preocupación en aquel tiempo no era otra que terminar con la redacción de la tesis doctoral. En 2004 volví a hablar con doña Carmen Saldaña y ella, tan generosa como su marido, cedió su legado documental a la Fundación Cultural Miguel Hernández.

En este trabajo se exponen algunos frutos de este primer acercamiento al archivo de Ramón Sijé, tanto los referidos a Miguel Hernández como, especialmente, la obra sijeniana. Reconozcamos que, para el hernandiano, siempre es apasionante bucear en las cartas de Miguel, escritos urgentes en los que éste pide a su amigo, desde el frío Madrid de 1932, dinero, gestiones, letras de ánimo. La carga afectiva, que siempre debería estremecernos, también podrá ser sentida por quienes se acerquen a este importante material.

La figura de Ramón Sijé, seudónimo de José Marín Gutiérrez (19131935), ha sido valorada hasta fechas recientes en relación con la influencia que ejerció en su amigo Miguel Hernández, y por ser destinatario de la célebre "Elegía" que éste compuso para él. Eutimio Martín, ${ }^{1}$ por ejemplo, afirma que «sin Miguel Hernández, Ramón Sijé no perviviría hoy más que en el nomenclátor callejero de la ciudad de Orihuela».

El mismo estudioso se pregunta, irónicamente, la razón del retraso en disponer de la obra sijeniana, si ésta goza de consideración tan alta entre sus exégetas. Es hora ya de desterrar prejuicios ideológicos y revisar la producción literaria de Sijé per se, no por su vinculación con el universal poeta oriolano,

\footnotetext{
1 “Ramón Sijé-Miguel Hernández: una relación mitificada”, en Miguel Hernández, cincuenta años después. Actas del I Congreso Internacional, Alicante, Comisión de Homenaje a Miguel Hernández, 1993, I, p. 43.
} 
ya que flaco favor haríamos tanto al primero como al segundo. Además, murió con 22 años, por lo que no podemos saber cómo hubiera madurado su concepción ensayística e ideológica.

Este artículo se estructura en las siguientes partes: una breve biografía, las facetas periodística (1929-1932) y ensayística sijenianas (1933-1935), El Gallo Crisis (1934-1935), y la relación de Sijé con Miguel Hernández. También han sido incluidos dos epígrafes más, debido a la relevancia de ambos: su amistad con Antonio Oliver Belmás y Carmen Conde, y el homenaje tributado a Gabriel Miró en 1932. De todas maneras, ello no significa que sean compartimentos estancos, muy al contrario, son permeables entre sí y la delimitación conceptual y temporal es sólo metodológica, orientativa. Por ejemplo, lo que Muñoz Garrigós² califica en su libro del "yo opinante" propio del género ensayístico es perceptible ya en los artículos periodísticos sijenianos. Es un proceso unitario. La significación de la conocida revista sijeniana dentro de su obra nos ha obligado a destacarla singularmente, al igual que su relación con el autor de Perito en lunas, sin que en este último caso ello, entendemos, conlleve caer en lo mismo que censuramos.

El objetivo general de este trabajo no es otro que ofrecer una visión general, pero no completa, como estímulo a futuros lectores de Sijé e investigadores de su obra.

Quisiera dedicar las páginas que siguen a los críticos que han invertido esfuerzo y tiempo en desvelarnos la luminosidad de la prosa de Sijé, cuales Dámaso Alonso con el Polifemo gongorino, y entre ellos cito a Vicente Ramos ${ }^{3}$ en primer lugar, que dedicó, entre otros sagaces escritos, el capítulo III de su libro Miguel Hernández, de 1973, y un temprano artículo en 1957; al eterno estudioso del ensayista, José Muñoz Garrigós, que tan buenos trabajos firmó y que dedicó su memoria de licenciatura a El Gallo Crisis ${ }^{5}$ y otros valiosos trabajos sobre dicha publicación periódica, que se citan al final del presente artículo; José Antonio Sáez Fernández, que dedicó su memoria de licenciatura al ensayista; Manuel Martínez Galiano, que prologó La decadencia de la flauta

\footnotetext{
${ }^{2}$ Vida y obra de Ramón Sijé, prólogo de Jesús Manuel Alda Tesán, Murcia-Orihuela, Secretariado de Publicaciones de la Universidad de Murcia-Caja Rural Central de Orihuela, 1987, p. 65.

${ }^{3}$ Madrid, Gredos, 1973, pp. [36]-88.

4 "Ramón Sijé", Información (Alicante) (2-IV-1957).

${ }_{5}$ El Gallo Crisis, memoria de licenciatura dirigida por Mariano Baquero Goyanes, Murcia, Universidad de Murcia, 1967.
} 
y el reinado de los fantasmas en 1973;6 mi amigo Gaspar Peral Baeza, que hizo realidad la publicación de dicho ensayo; Antonio Luis Galiano Pérez, que coordinó un interesante folleto en 1987; ${ }^{7}$ Ramón Fernández Palmeral, que ha dedicado una monografía al ensayo sobre el romanticismo; mi también amigo Francisco Martínez Marín; Antonio García-Molina Martínez; mi otro amigo, Antonio Peñalver García, y en general, a quienes no se dejan influir por valoraciones espurias sino que prefieren sacar sus propias conclusiones.

Deseo también agradecer la colaboración, siempre entusiasta, de la Biblioteca Pública del Estado "Fernando de Loazes", de Orihuela, y de su director, César Moreno.

Un reconocimiento especial, de afecto, merece la ya mencionada doña Carmen Saldaña, heredera de Sijé, por cedernos generosamente su importante legado para que futuros investigadores se acerquen a un intelectual completo que supo adelantarse al Concilio Vaticano II en la necesidad de que los católicos defiendan en la calle, cívicamente, su fe, y que no se queden inmóviles ante los sucesos que, entre 1934-1935, azotaron nuestro país.

\section{Biografía}

La trayectoria biográfica de Sijé está suficientemente bien trazada en la monografía de José Muñoz Garrigós, y aquí traemos algunos datos relevantes de su vida. En otro de sus trabajos, el mencionado crítico, ${ }^{8}$ confiesa que no se ha prestado suficiente atención a la personalidad humana de Sijé. Además, probablemente, la altura intelectual de sus escritos ha hecho mella en el escaso interés que ha despertado su trayectoria humana. Resulta totalmente injusto, ya que sus coetáneos valoraron, especialmente, el alto concepto de la amistad que tenía, por encima de su inteligencia. No se trataba de Ramón Sijé, el frío pensador refugiado en su gabinete, sino del Pepito amigo que disfrutaba con las tertulias, obras de teatro, y que ayudaba a quien se lo pidiera.

José Ramón Rufino Justino Antonio Marín Gutiérrez nació en Orihuela el 16 de noviembre de 1913 a las seis de la tarde y es bautizado diez días después en la catedral por el obispo de Orihuela, Ramón Plaza y Blanco. Sus padres,

\footnotetext{
${ }^{6}$ Prólogo de Manuel Martínez Galiano, Alicante, Instituto de Estudios Alicantinos, 1973.

${ }^{7}$ Ramón Sijé: Luces y sombras, Alicante, Caja de Ahorros Provincial de Alicante y Murcia, 1987.

8 "El itinerario andaluz de Ramón Sijé, según las cartas a su familia", en Homenaje a Justo García Morales. Miscelánea de estudios con motivo de su jubilación, Madrid, Asociación Española de Archiveros, Bibliotecarios, Musicólogos y Documentalistas (ANABAD), 1987, p. [821].
} 
José Marín Garrigós y María Presentación Gutiérrez Fenoll, poseían una tienda de tejidos en el número 27 de la calle Mayor, que ve decaer progresivamente sus ventas. Después nacerán sus hermanos Justino (1915) y María Dolores (1920). A la muerte de Sijé, la desgracia se abate sobre la familia: el padre muere atropellado por un carro, Justino fallece en 1946 y Mari-Lola en 1964.

El 25 de marzo de 1923 celebra su Primera Comunión en la Capilla de la Casa-Asilo de Ancianos Desamparados de Orihuela y para la ocasión preparó un recordatorio con texto propio.

Siete meses después, en octubre de ese mismo año de 1923, ingresó en el Colegio deSanto Domingo, regentado por los jesuitas, para cursar Preparatorio Inferior. Ahí coincidió con, entre otros, Miguel Hernández, Francisco de Díe y Augusto Pescador. En el curso 1925-1926 comienza el Bachillerato. A los doce años concursa en un premio que elogia la proeza de los aviadores Franco, Ruiz de Alda, Durán y Rada, al atravesar el Atlántico sobre las alas del "Plus Ultra", con el trabajo "España, la de las gestas heroicas", publicado en el número 41 de la revista madrileña Héroes el 31 de marzo de 1926. Sin embargo, a pesar de que algunos críticos así lo han sostenido, no lo gana.

En el curso 1926-1927 se incorpora al plan de Bachillerato de 1925. Se examina en junio de 1927, y en el curso 1927-1928 concluye sus estudios de Bachillerato Elemental, con sobresalientes.

El 13 de septiembre de 1928 publica su primer artículo periodístico en Orihuela, en Actualidad, sobre José M. ${ }^{a}$ Gabriel y Galán.

Entre marzo-julio de 1930 participa, como luego veremos, en la creación de la revista Voluntad. También colabora en El Pueblo de Orihuela, y adopta la firma de Ramón Sijé, anagrama formado por las letras del nombre de pila y del primer apellido. En junio de 1930, con apenas 17 años, concluye sus estudios de Bachillerato Universitario, con Premio Extraordinario, con lo que dejó de ser alumno de los jesuitas. Así, se alineó con otros grupos católicos, como la Juventud Antoniana. En ese sentido, en el número 5 de Voluntad, del 15 de mayo de 1930, se publica un texto sin firma muy elocuente: "La brillante velada de propaganda de la Juventud Antoniana", en el que se informa de la reunión celebrada el 4 de mayo en el Salón de Conferencias de la Caja de Monserrate, presidida por Luis Almarcha, en la que se hace referencia a José Marín como vicepresidente de la Comisión de Festejos. Además, y esto también resulta de interés, dicha organización disponía de un Cuadro Artístico Antoniano, en el que no es improbable que nuestro personaje también participara. 
El 21 de julio de ese intenso año de 1930 marcha a la localidad cordobesa de Fernán-Núñez, donde residían familiares suyos, y no regresará a Orihuela hasta el 18 de septiembre. Se conservan 47 cartas dirigidas a sus padres, de un total algo más numeroso. En estas misivas familiares, sin pretensión literaria, contrapunto de equilibrio emocional a sus artículos periodísticos de entonces, y a la posterior ascética mortificación de las palabras y de las ideas, es Pepito quien se nos presenta, no el futuro Ramón Sijé, preocupado por la salud de los suyos y por el transcurrir algo tambaleante del negocio familiar, los problemas propios de salud, su tremenda facilidad de hacer amistades superando diferencias de variado tipo, su afición por la fotografía, visitas a Sevilla y a otras ciudades andaluzas, etc. En ellas advertimos un muchacho con gran personalidad, admirado y respetado por su familia, y resuelto en la vida.

Tres días después de llegar a la citada localidad cordobesa, el 25 de julio, informa a los suyos de las interesantes conversaciones mantenidas con Antonio Romero, amigo de la familia, comunista declarado con el que compartirá paseos, cervezas y variados temas de discusión. Esta facilidad de hacer amigos será una tónica en su biografía, aún antes de la llegada en 1932 del Instituto de Segunda Enseñanza a Santo Domingo, en Orihuela, y exclaustración de la Compañía de Jesús.

También dispone de tiempo para colaborar en los ensayos de una obra teatral, como informa en carta del 25 de agosto: «¿Qué cuándo voy a ir?... cuando disminuya el calor (...) cuando se estrene una obrilla que estamos ensayando... que será pronto».

En ese mismo año de 1930 crea las revistas Voluntad y Destellos, ésta más de carácter literario que la primera. También participa en otras, por ejemplo, El Pueblo de Orihuela y Actualidad. Destacaría un precioso artículo, más de creación que periodístico o ensayístico: "Etopeya", publicado en el número 142 de El Pueblo de Orihuela, el 19 de noviembre de 1930.

En 1931 inicia los estudios de Derecho en la Universidad de Murcia como alumno libre, dirigido por su tío Francisco Marín Garrigós, que regentaba una academia. Entonces colabora en Diario de Alicante, órgano del Partido Republicano Radical, al que perteneció. Comienza a gestarse el homenaje a Gabriel Miró. A finales de ese año empieza a publicar en El Sol.

En el primer trimestre de 1932, se inicia el noviazgo de Pepito con Josefina Fenoll (nacida el 12 de junio de 1914), gracias a las visitas que ésta realiza a la casa familiar de los Marín-Gutiérrez para llevarles pan a diario. 
Una vez formalizado ese noviazgo, Sijé acudirá a la tahona. Es por ello que la legendaria tertulia ha quedado algo desvaída e imprecisa, por no decir que anulada como tal. En el archivo de Sijé se conserva un manuscrito, en mal estado, de 26 hojas, dedicado a su novia, fechado en enero de 1934, de una obra de creación propia, desconocida hasta la fecha: Farsa de amor y odio. Además, Augusto Pescador, que estudiaba en Madrid, en carta del 19 de marzo de ese año, le informa que se ha enterado por Miguel Hernández de sus amores, y que de este modo será mejor escritor pero peor pensador. Según su novia, a Sijé le gustaba dar largos paseos y tenía mucho sentido del humor.

En agosto de 1932 participa en el Campamento Universitario de Sierra Espuña (Murcia), donde conoce personalmente a Antonio Oliver Belmás, Carmen Conde, Carlos Martínez-Barbeito, Félix Ros, etc. En octubre se celebra el homenaje mironiano en Orihuela. En este año Sijé profundiza también la amistad con Raimundo de los Reyes y José Ballester, y en 1933 destacan sus colaboraciones para La Verdad de Murcia. Se enfría la relación con Ernesto Giménez Caballero y crece la de José Bergamín. Colabora en Cruz y Raya, El Día, de Alicante, Isla, de Cádiz, y ayuda en la publicación de Perito en lunas, de Miguel Hernández. Es invitado al Ateneo de Alicante y a la Universidad Popular de Cartagena.

Asiste en Orihuela a varias tertulias, como la del Palace Hotel, de tono literario; la del convento de los capuchinos, más filosófica; y existía una tercera, politizada, la del notario José M. ${ }^{\text {a }}$ Quílez y Sanz, a la que no acudía Sijé.

Entre junio de 1934 y enero de 1935 termina las seis asignaturas que le faltaban para concluir sus estudios de Derecho, con tres matrículas de Honor $\mathrm{y}$ tres sobresalientes.

En diciembre de 1934 forma parte de la Comisión Organizadora de la Asociación de Asistencia e Higiene Social de Orihuela, junto con Alfredo Serna, José M. a Quílez y Sanz (nombres que se repetirán en las páginas que siguen), Fernando Quintana y Jaime Sánchez Ballesta. Funda su tan famosa como escasamente leída revista El Gallo Crisis. A partir de ese momento, vivirá entregado a la dirección de la publicación periódica.

El último año de la vida deSijé, 1935, fue muy duro, aparte de frenético por las actividades múltiples y los plazos tan cortos en su trabajo. En enero de 1935 concluye sus estudios de Derecho con Premio Extraordinario de Licenciatura.

Además del enfriamiento de su amistad con Miguel Hernández, Sijé tuvo que soportar el rechazo de los intelectuales en Madrid a su revista, la 
urgencia por terminar su ensayo sobre el romanticismo, La decadencia de la flauta y el reinado de los fantasmas. Ensayo sobre el romanticismo histórico en España (1830-Bécquer), la polémica con el grupo sevillano de la revista Nueva Poesía y el empeoramiento de su salud.

El 19 de junio de ese año, Álvaro Arauz escribe a Sijé una carta en la que le anuncia el envío de su libro Voz y cuerda, publicado en ese mismo tiempo en Madrid por la prestigiosa Editorial Plutarco, le agradece una carta anterior con comentarios favorables a su poesía, y le pide que cuando reseñe su libro en Revista Hispánica Moderna le avise para comprar un ejemplar. No se publicó esa reseña en la revista, editada en Alicante por Juan Guerrero Ruiz, buen amigo de Sijé.

Pedro Pérez-Clotet, director de Isla, se dirige a Sijé para preguntar a diversos escritores, entre los que se encontraba Sijé, sus opiniones sobre la recuperación del romanticismo, ante su centenario. Las respuestas fueron publicadas en el número 7-8, de 1935,' Sijé criticó a Bécquer y afirmó que la "nueva literatura" no era más que una secuela posromántica. La revista Nueva Poesía, en su número 1 , de octubre de ese mismo año, comentó las opiniones sijenianas:

Lo que ya no puede discutirse, por ser inadmisible de todo punto, es la deshumanización incolora que advierte Sijé en el poeta de las Rimas. Hace falta no haber leído un solo verso de Bécquer o ser absolutamente irresponsable para juzgar de ese modo. No podemos admitir que Sijé hable de Gustavo Adolfo sin haberle leído.

Sijé respondió en El Sol del 10 de noviembre con "Polémica. Saber leer, saber comprender, saber falsificar". El ensayista acusa a los responsables de la revista andaluza de apropiarse de su postura respecto de la poesía surrealista

\footnotetext{
${ }^{9}$ El título de la encuesta fue "La nueva literatura ante el centenario del romanticismo". Se publicaron las respuestas y comentarios de Carmen Conde, Eduardo de Ontañón, Adriano del Valle, Guillermo Díaz-Plaja, Rogelio Buendía, Alfredo Marqueríe, Juan Gil-Albert, Ramón Sijé, Rafael de Urbano, Enrique Azcoaga, María Cegarra Salcedo, Andrés Ochando, Sánchez.-Trincado, José M. ${ }^{a}$ Luelmo, Ildefonso-Manuel Gil, José Ferrater Mora, Iván de Tarfe, Álvaro Arauz, María Luisa Muñoz de Buendía, Juan Ruiz Peña, Alfredo y Francisco Rodríguez Aldave, Tomás Seral y Casas, Julio Angulo, R. Olivares Figueroa, José Sanz y Díaz, José S. Serna, N. Sanz y Ruiz de la Peña, Eugenio Mediano Flores, Pascual Pla y Beltrán, Arturo Zabala, José Rodríguez Cánovas, Raimundo Gaspar, Juan Alcaide Sánchez, Luis F. Pérez Infante, Manuel de Rojas Marcos y Antonio Aparicio Errere. Puede consultarse la reciente edición facsímil de la revista andaluza: Isla. Hojas de Arte, Letras

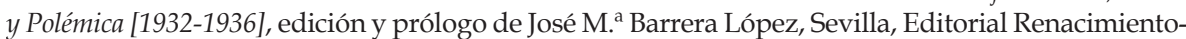
Servicio de Publicaciones, Diputación de Cádiz-Centro Cultural de la Generación del 27, 2006, pp. [158-168]. Las respuestas de Sijé se encuentran en las páginas [160-161].
} 
con el manifiesto de Nueva Poesía en el que critican Caballo Verde para la Poesía. El grupo sevillano, integrado por Juan Ruiz Peña, Luis F. Pérez Infante y Francisco Infantes Florido, respondió contundentemente a Sijé en el número 2-3 de su revista, "Saber leer, saber escribir, saber pensar", en noviembrediciembre de 1935. Descalifican a Sijé con las siguientes expresiones: «Todos sabemos que se trata de un mozalbete imberbe, pueblerino y pedantesco, por indigestión de letras (...) Su pensamiento es tan caótico, tan confuso, como la poesía superrealista, de la que - ¡oh, paradoja! - abomina».

Finalmente, Sijé les envió un escrito privado, en el que intentó una aproximación de posturas. La muerte lo impidió. El grupo sevillano expresó sus condolencias al padre del ensayista en carta fechada en Sevilla el 30 de diciembre. Miguel Hernández estaba al tanto de la polémica.

Hacia la primera quincena de diciembre, Sijé se encuentra en Madrid, según carta de Juan Guerrero Ruiz al padre del escritor oriolano datada el 28 de diciembre; quizás fuera allí para presentar su ensayo, cuyo plazo expiraba a mediados de ese mes.

En el archivo de Ramón Sijé ha aparecido una carta manuscrita, de principios de 1936, firmada por Antonio Azorín, muy deteriorada, dirigida a los padres de Sijé. En ella, por recomendación de Miguel Hernández, solicita algún número de la revista El Gallo Crisis. También informa que Hernández le "anuncia la edición del ensayo que deseo ya conocer", refiriéndose al citado ensayo sobre el romanticismo, La decadencia de la flauta y el reinado de los fantasmas, no publicado, como se sabe, hasta 1973 por el Instituto de Estudios Alicantinos, sobre el cual, Gaspar Peral Baeza ha publicado un elocuente artículo en el que relata sus peripecias editoriales. ${ }^{10}$ La tesis del romanticismo histórico y del romanticismo eterno procede de Eugenio D’Ors, aunque existen diferencias o discrepancias en la cuestión de las relaciones entre clasicismo y barroco. D’Ors niega la vinculación entre ambos y Sijé ve el segundo como la última consecuencia de la ratio escolástica. Sijé se obligó a estudiar doce horas diarias para preparar el ensayo, que no cumplía los requisitos que se exigían en las bases.

Hacia el 13 o 14 de diciembre se queja de un malestar estomacal. Fallece a las once de la noche del día de Nochebuena con 22 años.

\footnotetext{
10 “Miguel Hernández y el Ensayo de Ramón Sijé sobre el Romanticismo”, El Eco Hernandiano (Orihuela), 9 (primavera 2006), pp. 2-10.
} 
Según el Acta de Defunción publicado por José Antonio Saéz Fernández ${ }^{11}$ Sijé falleció en su domicilio «el día de ayer a las veinte y tres a consecuencia de toxi-infección intestinal, según resulta de la identificación facultativa y reconocimiento practicado».

Se trata de una septicemia al corazón, que es una enfermedad infecciosa grave, producida por la existencia de bacterias patógenas y productos de la misma en la sangre, según Sáez Fernández ${ }^{12}$ en el mismo libro.

Fue enterrado el día de Navidad, bajo la presidencia de los familiares de Sijé, José Martínez Arenas, el Padre Carrió y José M. ${ }^{a}$ Ballesteros. Según la prensa, no hubo distinción de ideologías en la concurrencia de personas que desearon despedirse de Pepito.

El 26 de diciembre aparece la noticia de la muerte de Sijé en El Sol. Vicente Aleixandre se entera por este medio e informa a Miguel Hernández. La familia de Pepito recibe los pésames de, entre otras personas, P. Félix García (30-XII-1935), Alfonso y Francisco Rodríguez Aldave y Ernesto Giménez Caballero (ambos, el 31-XII-1935), Álvaro Botella (3-I-1936), Jesús Alda Tesán (5-I-1936), Abelardo L. Teruel (7-I-1936), Carlos Martínez-Barbeito (principios de enero de 1936) y P. Buenaventura de Puzol (20-I-1936), desde la localidad murciana de Totana).

Ballesteros, en su artículo "Ha muerto Ramón Sijé", publicado en $L a$ Verdad del 28 de diciembre de ese aciago año, concluye su evocación con estas elocuentes letras:

La hora de la consagración de Ramón Sijé como escritor, no necesitará como condición precisa la de saltar la valla de su vida corporal. El despejo de su inteligencia, su voluntad y su buena estrella serán acicates que harán pueda saborear, aunque no tan pronto como él quisiera, las halagadoras caricias del triunfo.

A los pocos días de su muerte, el semanario oriolano Acción, de orientación derechista, le rinde homenaje el 30 de diciembre, en el que colaboran también significados escritores de izquierdas, como Jesús Poveda y Augusto Pescador.

\footnotetext{
${ }^{11}$ Textos sobre Ramón Sijé, edición y notas de José A. Sáez Fernández, Almería, Imprenta Cervantes, 1985, p. 102, n. ${ }^{\circ}$ 73. Sección Tercera, Tomo 114, Folio 219 Vto.

${ }^{12}$ Ibidem, p.102, n. ${ }^{\circ} 74$.
} 
Miguel Hernández, por su parte, compone su célebre "Elegía" en dos semanas. Muñoz Garrigós ${ }^{13}$ aporta testimonios de que el poeta era consciente de que se había conducido injustamente con su amigo.

$\mathrm{Al}$ poco de fallecer Sijé, según dejó escrito nuestro siempre recordado amigo Ramón Pérez Álvarez, el concejal Luis Carrió Pastor, abogado, fusilado en 1939, presentó una moción con fecha 7 de marzo de 1936, en sesión del 12 del mismo mes (Folio 56 y ss. del Libro de Actas) en la que propuso la rotulación de la plaza de Ramón Sijé, en vez de Pinohermoso. El texto, aprobado, decía:

Cree también este concejal interpretar los sentimientos justicieros y oriolanos de esta Corporación, honrando los valores de nuestra patria chica y con este objeto dedicarle un recuerdo a nuestro Ramón Sijé, muerto en plena juventud y cuando tanto esperaban de él las letras españolas de su inteligencia y laboriosidad, y propone que la plaza llamada en la actualidad de Pinohermoso y antes de la Pía, en lo sucesivo se denomine de Ramón Sijé, seudónimo del ilustre literato oriolano José Marín Gutiérrez.

El 14 de abril de 1936, día festivo, se celebró el descubrimiento del nuevo rótulo de la placa, con la participación de Miguel Hernández. Éste dijo aquel emotivo día:

Sé que su alma anda desde hoy - con la precipitación con que solían andar su corazón y su cuerpo - , anda y recorre esta plaza, y le complace su soledad cotidiana, que acrecientan las siestas, las lluvias y las casas cerradas.

En el archivo de Ramón Sijé también ha salido a la luz un díptico de 1936, en conmemoración del V aniversario de la proclamación de la República: "Fiestas que organiza el Excelentísimo Ayuntamiento de Orihuela en conmemoración del V Aniversario de la implantación de la 2. ${ }^{a}$ República Española". En el Programa de Festejos la Comisión de Festividades anunciaba para aquella mañana del martes 14 de abril de 1936, en los locales del "Grupo Escolar (Andenes de la Estación)" un reparto de fiambres "a los pobres de solemnidad". A las diez de la mañana una manifestación que partió del Ayuntamiento (sito en la actual Plaza Nueva) en dirección a las nuevas rotulaciones de calles. Se anuncia que la plaza del Duque de Pinohermoso

13 “Miguel Hernández y Ramón Sijée, en F. J. Díez de Revenga y M. de Paco (eds.), Estudios sobre Miguel Hernández, Murcia, Universidad de Murcia, 1992, p. 158. 
llevaría el nombre de "Ramón Sijé", así como la de Abate Penalva (Arriba) por la de la Libertad. Después tuvo lugar una recepción en honor de los niños del Instituto y Escuelas Nacionales en el Grupo Escolar de los Andenes, y un concierto en la Glorieta de Gabriel Miró a cargo de la Banda de Alcantarilla. A las 12 del mediodía, "Comidas extraordinarias en los establecimientos Municipales". Por la noche, de 9,30 a 12 horas, se celebró una Velada Musical en la Plaza de la República, con la elección de "Señorita República 1936". Los actos festivos concluyeron con una traca valenciana.

Por desgracia, y en una decisión, en mi opinión, equivocada, la Comisión Permanente del Ayuntamiento de Orihuela, en sesión del 12 de marzo de 1958, revoca esa rotulación (Folio 86 y ss., apartado F) y la cambia por la actual de Marqués de Rafal, y Ramón Sijé pasa a denominar una vía totalmente secundaria.

En carta de Luis Almarcha del 14 de febrero de 1961 a Antonio GarcíaMolina, le sugiere que se recoja todo el material de Sijé para ser publicado. No pasó de un intento vano.

Fue instaurado, por el Ayuntamiento oriolano, el Premio Ramón Sijé de Ensayo en 1971, efímero y sin consecuencias prácticas en el reconocimiento a nuestro autor. La publicación en 1973 de la edición facsímil de El Gallo Crisis, ${ }^{14}$ por el mismo Consistorio, y del ensayo sobre el romanticismo en ese mismo año, por el entonces Instituto de Estudios Alicantinos, dependiente de la Diputación alicantina, no tuvo otros criterios que no fueran estrictamente literarios.

En 1985 (aunque el díptico correspondiente indique 1987), con ocasión del L aniversario de su muerte, la sección de Obras Sociales de la Caja de Ahorros de Alicante y Murcia patrocinó una semana cultural, organizada por el Instituto Gabriel Miró de Orihuela, del 16 al 20 de diciembre de aquel año. El "Homenaje a Ramón Sijé en el 50 aniversario de su muerte", contó con la inauguración, a las 18,30 horas del 16 de diciembre, de una exposición de paneles sobre la vida y obra de Sijé, realizada por alumnos de COU del Centro. Dicha muestra, estaba estructurada de la siguiente forma: notas biográficas y juicios sobre Sijé, pequeña antología de su obra, la Orihuela de Sijé, y la relación de éste con Miguel Hernández. El profesor Muñoz Garrigós ofreció, a las 19 horas del mismo día, la conferencia "Injusticias que pesan sobre la memoria

${ }^{14}$ El Gallo Crisis, edición facsímil, prólogo y comentarios de José Muñoz Garrigós, Orihuela, Publicaciones del Excmo. Ayuntamiento de Orihuela, 1973. (Existió una segunda edición en 1975) 
de Ramón Sijé". El día 20, a las 19 horas, tuvo lugar una mesa redonda con la participación de Juan Bellod, Mariano Cremades, Antonio García-Molina, Manuel Molina, José Muñoz Garrigós y José Antonio Sáez Fernández. El moderador no fue otro que Vicente Ramos.

La Fundación Cultural Miguel Hernández y la Asociación de Amigos de Orihuela organizaron un homenaje al ensayista en el cementerio oriolano el 24 de diciembre de 2005, con motivo del LXX aniversario de su fallecimiento. Por esas mismas fechas, Ramón Fernández Palmeral ${ }^{15}$ editó a su costa un libro sobre el ensayo sijeniano del romanticismo.

Es de esperar, por parte del pueblo natal de Sijé, un reconocimiento más evidente, que bien podría ser la edición de toda su obra, en un volumen accesible a todas las posibles personas interesadas.

En definitiva, no es justo enjuiciar al hombre al mismo tiempo que se critica su obra, ya que, además, Sijé no se vio impelido a tomar posiciones ideológicas motivadas por los sucesos que, algo más de seis meses después de su muerte, tuvieron que tomar amigos suyos, como Miguel Hernández. Su obra no estaba cerrada, al contrario, se encontraba en permanente progresión. Murió con 22 años, por lo que nunca sabremos qué camino hubiera tomado, ni en la vida ni en la escritura. La realidad única y esencial es que fue un intelectual en el más amplio sentido del término, preocupado por el presente y futuro, tanto de Orihuela como del resto de España. Creo que son méritos más que suficientes para agradecérselos, y éste es nuestro objetivo último con las presentes líneas.

\section{Periodismo}

En la Orihuela de la Dictadura del general Miguel Primo de Rivera, la fiebre editora de publicaciones periódicas fue una de las más destacables de las características, fenómeno que se repitió en el resto del país. Desde 1929 hasta 1936, nueve cabeceras convivieron en la ciudad del Segura: El Pueblo de Orihuela, Actualidad, Renacer, Voluntad, Destellos, El Clamor de la Verdad, El Gallo Crisis, Acción y Silbo. Los continuos enfrentamientos ideológicos se canalizaban a través del periodismo local.

\footnotetext{
${ }^{15}$ Simbología secreta de 'La decadencia de la flauta y el reinado de los fantasmas', de Ramón Sijé, estudio e ilustraciones de Ramón Fernández Palmeral, prólogo de José A. Sáez Fernández, Alicante, Editorial Palmeral, 2005.
} 
La prensa local será determinante en la plasmación de la evolución intelectual de Sijé y también de Miguel Hernández. Abelardo L. Teruel, Azorín, Gabriel Miró y, sobre todo, José M. ${ }^{a}$ Ballesteros, ${ }^{16}$ fueron los guías de aquellos muchachos a los que les dominaba la pasión por la escritura.

En el caso de Sijé, empezó como periodista divulgativo. Cuando profundice en este tipo de artículos, se hará ensayista, aunque sui generis, ofrecerá su opinión personal, no la de un crítico erudito. Hasta, más o menos, 1933, los estudiosos sijenianos delimitan su senda periodística, aunque las fechas son aproximadas y no pueden ser tomadas como definitivas. De los artículos de 1930 a los de 1932 se advierten múltiples diferencias. Es un periodo formativo muy interesante.

La trayectoria como periodista de Sijé se inicia en Voluntad, tras los primeros brotes de la revista madrileña Héroes y de la oriolana Actualidad. También hemos descubierto colaboraciones suyas en la revista tarraconense Juventud. Revista literaria mensual, concretamente en el número 2 (22-XI-1929), 3 (22-XII-1929), 4 (22-I-1930), 5 (22-II-1930) y 6 (22-III-1930), que convendría analizar con detenimiento e integrarlas en unas futuras obras completas. La revista tenía como finalidad "contribuir a modelar perfectos literatos", según leemos en el primer número, del 22 de octubre de 1929. Estos trabajos periodísticos son desconocidos y aportan una faceta asimismo insólita en José Marín Gutiérrez (no utiliza el seudónimo literario que le daría fama), como es la de encargado de la divertida y didáctica sección de pasatiempos, así como cronista de la valoración realizada en Orihuela de la nueva revista catalana, con "Ecos de Orihuela", publicado en la página 11 del número 2, del 22 de noviembre de 1929. En el número 3, del 22 de diciembre de 1929, se anuncia la inminente publicación del primer capítulo "de la preciosa narración Las memorias de un mendigo, por D. José Marín Gutiérrez", así como la "Interesante sección de Pasatiempos, a cargo de D. José Marín". También se informa de que "En breve comenzaremos a publicar la bella novelita Sombras, original de nuestro dilecto colaborador D. José Marín Gutiérrez". Una parte de Las memorias de un mendigo es publicada en la página 3 del número 5, del 22 de febrero de 1930. En ese mismo número el periodista José Marín publica

\footnotetext{
${ }^{16}$ El cual, en la página 5 del número 7 de Voluntad, correspondiente al 15 de junio de 1930, dedicó la primera noticia sobre la vida y obra del incipiente poeta, seguramente espoleado por Sijé: "Pastores poetas".
} 
"Orihuela", en las páginas 2 y 3, con la intención de describir su pueblo natal, pero ofreciendo rasgos temporales que resultan interesantes para calibrar y valorar la objetividad del ya avezado cronista:

Orihuela va por el camino de la civilización y del progreso y mientras que se anuden todos estos elementos oriolanos, habrá progreso y habrá civilización y que sirvan de criterio normativo y directivo las palabras que flamean en nuestro escudo.

Los "elementos oriolanos" no son otros que el Ayuntamiento, presidido entonces por Francisco Díe Losada, y el pueblo:

Ayudan también a esta labor los periódico locales Actualidad, órgano de la juventud oriolana dirigida por el joven abogado y sutil ingeniero don Tomás [López] Galindo, El Pueblo de Orihuela, centro de los sindicatos católicos, y Renacer, de reciente publicación.

Actualidad, cuyo primer número salió el 23 de febrero de 1928 y el último el 26 de febrero de 1931 (151 números en total), era propiedad de Alejandro Roca de Togores, y el redactor jefe, Tomás López Galindo. Durante sus tres años de actividad, reflejó la línea más progresista de las derechas oriolanas. Aparecen las firmas de Juan Bellod Salmerón, José M. ${ }^{a}$ Ballesteros, Fray Buenaventura de Puzol y la del propio Sijé, aunque hasta 1930 no adopta ese seudónimo. Pepito Marín no publica en este semanario hasta el 13 de septiembre de 1928, con un artículo sobre Gabriel y Galán, y ni siquiera contaba quince años de edad. Fue el primero de catorce trabajos, hasta el 23 de octubre de 1930.

José M. ${ }^{a}$ Ballesteros, en un emotivo artículo, "Ha muerto Ramón Sijé", publicado en La Verdad el 28 de enero de 1936, admite que su amigo se inició en el mundo de las letras "en revistas semanales, todos empezamos así". La influencia del novelista en Sijé es elocuente en el objetivo de censurar los defectos de Orihuela, y le dedicará "Oriolanas y Orihuela", en Voluntad, el 15 de mayo de 1930, y "Un banquete a Ballesteros", en la misma revista, dos semanas después, en donde Sijé afirma:

Ha llegado a mis oídos, periodísticos ante todo (...) Pero no por eso, al dar un abrazo al maestro Ballesteros, pero camarada también, unido a mí por lazos de un periodismo (...) Y desde lejos brindaré por Ballesteros. No con la copa en la mano sino con la pluma, que es bebida y alimento de periodistas. 
No sólo Sijé rindió tributo de amistad y gratitud: Miguel Hernández escribió "Ofrenda", dedicado a Ballesteros, en Actualidad, el 5 de junio de 1930; Abelardo L. Teruel: tres artículos en Actualidad, uno en El Correo (Alicante) y otro en Diario de Alicante, del 27-IX-1928, 13-II-1929, 29-V-1930, 15-V-1930 y 10-X-1935, respectivamente. Ballesteros, por su parte, escribirá un artículo consagrado a Sijé el 4 de julio de 1932 en Diario de Alicante. José M. ${ }^{\text {a }}$ Pina Brotóns ${ }^{17}$ reconoce ese liderazgo de Ballesteros sobre Sijé: "Ramón Sijé es intelectual y estilista como su maestro José M. ${ }^{a}$ Ballesteros". Aunque sensiblemente menor, el ascendiente de Juan Sansano también se deja notar en la relevancia del tema de la muerte, entendida ésta como liberación.

Jesús Poveda ${ }^{18}$ recuerda que conoció a Sijé en 1928, y le impresionó su profunda vida intelectual; el segundo colaboraba en una revista cordobesa, en la que incluyó un trabajo del primero sobre Beethoven. Sin embargo, la memoria de Poveda erraba el origen de la revista: se trataba de Juventud. Revista literaria y mensual, editada en Tarragona, en cuyo número 3, página 11 del 22 de diciembre de 1929, fue publicado el trabajo "El sordo de Bonn", del propio Poveda. Más adelante, Poveda ${ }^{19}$ trae a colación en sus memorias la génesis de Voluntad, de la que fue fundador y redactor, al menos esto último hasta el número 4, del 30 de abril de 1930, cuando descubrió un plagio de Emilio Salar Luis, del que también se conserva en el archivo de Ramón Sijé su renuncia manuscrita a seguir formando parte de la redacción de la revista, dirigida a Sijé, y la dimisión de otro redactor, Antonio Estevan. El primer número de la publicación apareció el 15 de marzo de 1930 y el último, el 31 de agosto del mismo año. Aguantó trece números. El farmacéutico Alfredo Serna ayudará al buen fin de la revista quincenal. El título de la revista procedía de un ejemplar de La Voluntad, de Azorín que llevaba Poveda. Según éste, ${ }^{20}$ Sijé decidió que se llamara Voluntad. Poveda pidió colaboración a Fenoll, y por la mediación del primero Sijé conoció al segundo. Por Fenoll, según Poveda, ${ }^{21}$ ambos conocieron a Hernández. Sijé publica nueve trabajos en la revista.

Voluntad no tenía adscripción política alguna, según se desprende del editorial del número 1, del 15 de marzo de 1930, aunque destacamos su línea

\footnotetext{
17 “Ramón Sijé", Destellos, 8 (28-II-1931), p. 4.

${ }^{18}$ Vida, pasión y muerte de un poeta: Miguel Hernández, México, Ediciones Oasis, 1975, p. 32.

${ }^{19}$ Ibidem, p. 33.

${ }^{20}$ Ibidem, p. 34.

${ }^{21}$ Ibidem, p. 35.
} 
progresista. Sijé recibe una carta de Felipe Gil Casares, catedrático de Derecho Civil en la Universidad de Santiago de Compostela, fechada el 19 de mayo de ese 1930, en la que le adjunta unas cuartillas ("El espíritu revolucionario") para ser publicadas en Voluntad, como así será el 30 de ese mes.

En la misma revista, Sijé publica un muy interesante artículo en el número 9, del 15 de julio de 1930, con el título "En los momentos felices de nuestra historia", en el que pide una urgente transformación industrial en Orihuela, a pesar de que con el cambio algunas tradiciones pueden perderse: «Para Orihuela: ¡Oriolanos! Seamos Teodomiros - aún en el aspecto grosero de Teodomiros López, burgueses y recaudadores - , pero seamos Teodomiros».

El 15 de marzo de 1930 Sijé utiliza por vez primera su conocido seudónimo en el artículo "Silueta Quinteriana", en el primer número de Voluntad, en el que también publica un trabajo remitido un mes antes, el 11 de febrero, por los hermanos Álvarez Quintero: “La pandereta (Breve defensa de las "panderetas" españolas en relación con las de otros países)". En la revista se conocen mejor y traban relación de amistad Carlos Fenoll, Miguel Hernández, Jesús Poveda y el propio Sijé. Esta amistad hará posible la creación de Destellos.

Desde 1929 José Marín utiliza diversos seudónimos: Chás (utilizado por vez primera el 20 de junio de 1929 en Actualidad), Babbitt (usado en los textos más políticos, como "De re politica" o "Estudiantina Revolucionaria", publicados ambos en Voluntad el 30 de abril de 1930, y "Meditaciones políticas" y "República Española", en Destellos, 15 de enero de 1931 y 15 de abril del mismo año), José Oriolano, Lola de Orihuela, Rataplán, Sascha, Marcelo de Nola, Don Pepe, ERRE TE, etc.

Desde el 31 de agosto de 1930, que desaparece Voluntad, hasta la aparición de Destellos, el 15 de noviembre de ese mismo año, nuestro escritor colaboró, como hemos comentado, en Actualidad, y El Pueblo de Orihuela (no hemos encontrado más que tres trabajos publicados el 22 de octubre de 1930, 28 del mismo mes y año, y 19 de noviembre, firmados como Ramón Sijé).

En 1930 formó parte de la Comisión Pro-Homenaje a Jacinto Benavente, y publicó un artículo sobre el dramaturgo en Destellos, el 15 de enero de 1931: "Ante el homenaje a Jacinto Benavente". Tres meses después, el 15 de abril de 1931, también publicó "Benavente y la bohemia", en la misma revista, Destellos, y apareció, sin firma y una página después, la noticia de la "Suscripción Nacional para el Monumento a Benavente", bajo el epígrafe 
general de "Homenaje a Benavente". Se avisa que "La Comisión Organizadora ha encargado a nuestro periódico para la recaudación en esta provincia".

La revista Destellos tenía como subtítulo "Revista literaria quincenal". El primer número salió el 15 de noviembre de 1930, y el último, el trece, el 15 de mayo del año siguiente. En su último número podemos leer: "Destellos nació siendo una revista exclusivamente literaria y, como nació, muere".

Los fundadores fueron José M. Ballesteros y Ramón Sijé. El primero fue el director, pero Sijé la sacó adelante. En uno de sus primeros números se afirma:

resurgir de juventud, juventud que piensa, juventud que lee, juventud que trabaja. Despierta ahora, Orihuela dormida. Eso es una esperanza. Optimismo puro. Y es también una lección: la escuela y la despensa.

Colaboraron en esa revista Miguel Hernández, Carlos Fenoll, Juan Sansano, José Ballester, etc. También el murciano Raimundo de los Reyes, con cuatro poemas bajo el título de "Cancionero", en la primera página del número 6, del 31 de enero de 1931. En el número 11, del 15 de abril de 1931, Babbit saluda a la República: "el triunfo rotundo de la libertad y del civismo, el triunfo indiscutible de la cultura ciudadana", por el cambio moderado de régimen. También se afirma:

Hoy que el trabajo corporal e intelectual entrañablemente abrazados dan a luz un pueblo nuevo y sensato; hoy que ondea en todos los mástiles la flamante bandera tricolor, España, nuestra Patria, recordando las gestas gloriosas de sus antepasados, da un salto, y de él, se coloca a la cabeza de la civilización y de la intelectualidad del Mundo.

El artículo fue recogido en el número 70 de Renacer del 21 de abril de ese año, sin saber que Babbit era uno de los seudónimos de Sijé, como hemos visto.

El 28 de febrero de 1931 Sijé publica su único poema conocido: “De la vida de los hombres que sufren. Circo", en Destellos, que flaco favor hace a Sijé como

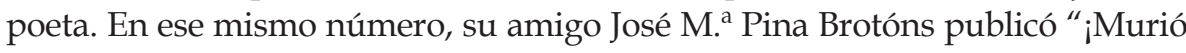
Ramón Sijé!", un artículo interesante por cuanto el autor del mismo certifica que Sijé ha dejado de ser periodista local y despega ya como ensayista. Por ello, como hemos comentado, las fechas planteadas anteriormente son aproximadas y sólo tienen una motivación clasificatoria, y no definitiva.

En la segunda mitad de ese 1931, tras la desaparición de Destellos, su empresa hasta ese momento más literaria, Sijé deja de publicar en la prensa local y lo hace en medios regionales y nacionales. Fue corresponsal de Diario 
de Alicante, órgano del Partido Republicano Federal, del que Sijé redactó, según algunos críticos, su Manifiesto tras la proclamación de la República. Voluntad y Destellos serán su banco de pruebas periodístico para culminar como ensayista en El Gallo Crisis.

A finales de ese agitado 1931, con su ingreso en la Universidad de Murcia en junio, hace posible que entre en contacto con un interesante grupo de escritores. Por esas fechas mantiene también correspondencia con Pedro Mourlane Michelena.

El 12 de noviembre de 1931 Sijé recibió una carta de Joaquín Aznar, director del diario madrileño La Libertad, en la que le remite adjunto un trabajo que el primero envió al concurso del citado periódico con el lema "Una paloma", señalado con el número 352.

Publicó también en El Sol el 25 de noviembre de 1931 el artículo “Tristeza y ruina estética de la conversación española", en donde critica la negación de la típica tertulia, con intercambio de impresiones, y no imposición de juicios. Precisamente, Ricardo Baeza, redactor del diario fundado por Ortega y Gasset, ejercerá una importante influencia periodística en el oriolano, según se constata en el artículo "Acotaciones a Musset. Para amantes y poetas", publicado en Diario de Alicante el 10 de junio de 1932.

Ignacio Balanzat, secretario de redacción del semanario madrileño Ahora, le escribe una carta, con membrete de Editorial Estampa, el 24 de junio de 1932, informándole que la corresponsalía en Alicante ya no está vacante. Sin embargo, Francisco Jiménez, secretario del Semanario Independiente jAdelante!, de la localidad cordobesa de Fernán Núñez (lugar de veraneo familiar), le pide el 16 de julio, un mes después, colaboración para un extraordinario con motivo de la Feria del 14 al 17 de agosto próximo. En un escrito incluido al final de la carta formal, una persona conocida suya del pueblo, le anima a mandar algo, ya que en anteriores ocasiones no lo ha hecho. Debió surtir efecto la apostilla de marras porque en el número 22, extraordinario correspondiente al 7 de agosto, se publica un breve texto firmado por Ramón Sijé sobre Teófilo Gautier y la visita de éste a Córdoba, relacionándolo con Góngora.

En 1933 Sijé ya no publicó en Diario de Alicante, quizás por la radicalización de su línea editorial. A partir de este momento, el periodismo en Sijé tomará otros aires, en la cercana Murcia y su diario La Verdad, más escorado al ensayismo que al periodismo. La amistad con Raimundo de los Reyes y José Ballester será decisiva en este aspecto. 


\section{Amistad con Antonio Oliver Belmás-Carmen Conde}

Ramón Sijé publica "Notas a un poeta" en Diario de Alicante del 19 de julio de 1932, una reseña elogiosa de Tiempo Cenital, de Antonio Oliver Belmás, salido en abril de ese mismo año de las prensas de Ediciones Sudeste, dirigidas por Raimundo de los Reyes, amigo de Sijé. El 28 de julio el escritor cartagenero le escribe una carta agradeciéndole su crítica. Dicha carta le fue remitida por el director del periódico, Emilio Costa, en carta del 30 de julio. Un mes más tarde, en agosto, se conocen personalmente Antonio Oliver Belmás y Carmen Conde y el oriolano en el Campamento Universitario, organizado por la FUE (Federación Universitaria Escolar), en Sierra Espuña, en el que también participó el gallego Carlos Martínez-Barbeito y con el que Sijé hizo una gran amistad. La simpatía mutua de Sijé y los Oliver-Conde, así como el fervor común hacia la prosa de Gabriel Miró y la búsqueda de directrices intelectuales socializantes en las que la cultura y educación eran fundamentales (ahí está la Universidad Popular de Cartagena como ejemplo), superaba diferencias ideológicas, y nos reafirma en la idea de que tachar de intolerante y fascista al primero resulta injusto. Se consolidó un eje cultural de primer orden entre Cartagena (los Oliver-Conde, Rodríguez Cánovas, etc.)-Murcia (Raimundo de los Reyes, José Ballester, etc.) y Orihuela (Sijé y su grupo), el Levante literario, que superaba también barreras territoriales y provinciales y aspiraba a servirse de la cultura como nexo principal de unión. Díez de Revenga ${ }^{22}$ ha trabajado en esta línea.

A través de la estrecha amistad de Sijé con el matrimonio Oliver-Conde, Miguel Hernández verá abiertas las puertas de la Universidad Popular, que dirigía la pareja, y será invitado en varias ocasiones, como es bien sabido por los estudiosos hernandianos. Además, gracias a las relaciones de Sijé con De los Reyes, el poeta vio publicado en 1933 su primer libro y contó con la eficaz amistad de Juan Guerrero Ruiz.

Antonio Oliver Belmás evocará al amigo en un sentido artículo, "Proyección de Ramón Sijé", publicado en la página especial de "Letras y Artes", la cuarta, a éste consagrada en La Verdad el 30 de enero de 1936, del que entresacamos unos interesantes fragmentos que hablan por sí solos:

${ }^{22}$ Revistas murcianas relacionadas con la generación del 27, Murcia, Academia Alfonso X El Sabio, 1979 , p. 239. 
¡Qué sorpresa la mía, más inesperada, cuando en el Diario de Alicante leí su nota, la que más me ha agradado, sobre mi libro Tiempo Cenital. ¿Quién era Sijé? ¿Qué apellido era éste tan desconcertante? ¿Qué desconocido, pero tan verdadero amigo tenía yo, que comprendía con tanta evidencia, tan totalmente, tan angélicamente, una poesía que los más rechazaban, llegando a algunos en su repulsa a formas bajas y groseras? Trabé conocimiento personal con Sijé a más de mil metros sobre el nivel de la vida diaria. Él estaba en Espuña, con ocasión del Campamento Universitario, con otros jóvenes que en su tienda de campaña leían cuando yo llegué a Rosalía de Castro. Los amigos de Sijé, no obstante la lectura, llevaban barbas antirománticas que daba pena contemplarlas. José Marín, adolescente, rompía el coro de barbudos. Paseé con él entre los pinos. Le tomamos unas fotografías en la que su rostro de luna plena sonríe sobre la cresta de los montes. Más tarde, Ramón Sijé estuvo en la Universidad Popular de Cartagena y nos leyó, ante la general estupefacción, unas magníficas cuartillas sobre Miró y Orihuela. Él fue, con Miguel Hernández, el organizador de un homenaje olezano a Miró, del que queda un busto en una apacible glorieta y una edición de El Clamor de la Verdad, el periódico que aparece en la Oleza de Nuestro Padre San Daniel.

Después del acto, el responsable de la Universidad Popular de Cartagena reconoce que no volvió a ver a Sijé, si bien en 1933 ofreció en la ciudad portuaria una conferencia sobre Perito en lunas, acompañado de Miguel Hernández. Oliver Belmás, en este interesante trabajo, afirma que, sobre Sijé, Miguel Hernández

me habló en Madrid y en Cartagena de su consunción espiritual, de su arder creciente y prematuro, para lo que todos tenemos que iluminar. $\mathrm{Su}$ estilo - Gracián, Quevedo - cada día se hacía más maduro y, como ha dicho Juan Ramón, hemos perdido con su tránsito una figura de la gran crítica literaria española.

En este sentido, Emilio Ríos ${ }^{23}$ recuperó el texto juanramoniano en el volumen de aforismos Ideolojía-II, que lleva por título "Ramón Sijé":

Terminando de copiar esta serie, leo en El Sol [26 de diciembre] la tristísima noticia de la muerte de Ramón Sijé (de Orihuela, como Miguel Hernández Giner, el estraordinario poeta); noble esperanza de la crítica mejor española.

\footnotetext{
${ }^{23}$ Justificación, glosas y sugerencias de Emilio Ríos, Moguer, Ediciones de la Fundación Juan Ramón Jiménez, 1998, p. 33, aforismo número 167.
} 
Mi pésame más hondo, desde aquí, a Miguel Hernández y a nuestra primera juventud.

Oliver Belmás concluye su artículo y ofrece

de antemano mi esfuerzo para recopilar su obra y difundirla. Tengamos conciencia regional, y aquí hablo, naturalmente, para los que sobre todas las cosas sienten la hermandad ante la cultura, quiero nombrar a los que tienen noción, no sólo del tiempo que nos ha tocado recorrer bajo esta faz mediterránea, sino de aquellos con los que, forzosamente, hemos de recorrerlo.

Carmen Conde recordará, en varias ocasiones, a los dos amigos, Ramón Sijé y Miguel Hernández. En el archivo de Ramón Sijé ha aparecido una copia mecanoscrita, recientemente editada, ${ }^{24}$ de una conferencia de Conde titulada Tres inolvidables adolescentes de Orihuela y uno de La Unión, ofrecida en Orihuela el 20 de marzo de 1955 en la Tabla Redonda de la Poesía, con motivo de la I Asamblea de Poetas y Escritores del Sudeste Español, celebrada en Orihuela los días 19 y 20 de ese mes. En ella, Carmen Conde describe del siguiente modo a Sijé:

Para mí, Ramón Sijé era un asombro de criatura, un portento de muchacho. Su palabra era un primor de justeza, de luz, de armonía. Su pensamiento era nítido, diamantino; casi científico a fuerza de precisión. Desde que lo sentí trepidar a mi lado yo estaba convencida de que iba a pasarle algo, de que un ángel se lo llevaría de repente porque él no era para estar aquí. Ya había tenido yo la suerte inmensa, y los que le conocieron saben que era una inmensa suerte, de haber tratado personalmente a Gabriel Miró, origen de todo lo hermoso que produzca Orihuela en varios siglos de literatura. Y si Miró me producía una sensación de reposo admirado indefinible, el pequeño, vibrante Ramón Sijé, su hijo de letras, me la producía de frenética inquietud. Nervios, voz, movimiento, pasión, visión del futuro, responsabilidad del pasado. ¿Qué no supo sentir aquel adolescente extraordinario que era Ramón Sijé?

\section{Homenaje a Gabriel Miró}

El domingo 2 de octubre de 1932 se celebró en Orihuela una "Romería lírica a Oleza con motivo de la inauguración del monumento al escritor

\footnotetext{
${ }^{24}$ Orihuela, Fundación Cultural Miguel Hernández, 2007.
} 
levantino Gabriel Miró", homenaje público al novelista, fallecido dos años antes en Madrid, concretamente el 27 de mayo de 1930. La idea del homenaje fue celebrarlo el 27 de mayo de 1932, en la conmemoración del segundo aniversario de su desaparición, pero se retrasó. Sijé dejó escrito:

Con Miró comienza la nueva historia, el certero modo de ver la vida estilizada y clara, el hervor de la sangre fecunda, el destilamiento de una personalidad, el moderno testamento.

Fue creada una Comisión Pro-Homenaje a Gabriel Miró, de la que José María Ballesteros era su presidente, y Sijé el secretario. Algunos críticos, como José Guillén García, José Muñoz Garrigós (en 1977, aunque después cambió de opinión), José Antonio Sáez Fernández, Ana M. Reig Sempere, etc., han querido ver en dicho acto el símbolo en torno al cual se consolidó la llamada "generación oriolana de 1930". No queremos entrar aquí y ahora en refutar la existencia de semejante "generación literaria", sobrevalorada en exceso por la relevancia de algunos de sus supuestos miembros. José Guillén García, ${ }^{25}$ en un recordado artículo, aparte de incluir una muy útil "Addenda bibliográfíca" ${ }^{26}$ mironiana de los miembros de dicha generación, sitúa en sus justas coordenadas estéticas las concomitancias entre Miró y los jóvenes escritores que le reivindicaron: ${ }^{27}$

1. Postura crítica frente a la línea tradicional.

2. Intensa sensibilización ante la belleza con el entorno paisajístico.

3. Preocupación por arrancar a la palabra escrita todos los secretos de efectividad expresiva.

La cosmovisión mironiana se diversificaría, según Guillén García, y aglutinaría parcialmente en los miembros (los hermanos Sijé, Miguel Hernández, Carlos Fenoll, Jesús Poveda, etc.), al igual que la multiplicidad de facetas del barroquismo de Orihuela, dispares a cada uno de ellos. Sijé asimilará una amalgama de religiosidad y barroquismo, procedente este último de la caracterización mironiana de "Oleza", trasunto literario de Orihuela, como luego veremos.

\footnotetext{
25 “Miró y la generación olecense de 1930”, Monteagudo, 65 (1979), pp. 21-26.

${ }^{26}$ Ibidem, pp. 25-26.

${ }^{27}$ Ibidem, p. 23.
} 
Gabriel Sijé ofreció hacia el 27 de mayo de 1941 la conferencia “El hombre y el paisaje (Hacia una definición mironiana)" en el Casino Orcelitano. Antonio García-Molina Martínez ${ }^{28}$ la publicó en un trabajo. El mismo García-Molina Martínez es autor de un texto de cuatro hojas mecanografíadas inéditas, leídas con motivo de "Romería lírica y Jornada Literaria" el 6 de octubre de 1979 en Orihuela, en homenaje a Gabriel Miró en el centenario de su nacimiento, en el que evoca aquel acto de 1932.

Por su parte, José Muñoz Garrigós ${ }^{29}$ afirma que Miró es guía generacional del grupo porque descubrió las coordenadas del ser de Orihuela: religiosidad, barroquismo y sentimiento del paisaje. Sin embargo, después el propio Muñoz Garrigós ${ }^{30}$ sostiene que Miró no fue guía de la citada generación del 30: "no lo es por su estilo, por su forma de escribir, por su prosa sensorial".

Para Miró, la belleza nace de la palabra misma, fecundada por el sentimiento, sin desgarrones; por el contrario, para Sijé la palabra es el resultado de un violento esfuerzo de ascética personal, casi no tiene forma, sólo tiene significado, el que desea su autor, que recrea constantemente en busca de la verdad. Para Sijé, la pasión por la verdad no es un juego frío, intelectual e inhumanizado, sino una búsqueda dialéctica e íntimamente vivida.

En el archivo de Ramón Sijé ha aparecido un texto manuscrito, compuesto de tres hojas numeradas, muy interesante porque denota un profundo conocimiento de la poesía y, concretamente, de la estética mironiana, en donde, como primera cita, con el título "Día armónico", se da inicio a los conocidos versos de Miguel Hernández "Hoy el día es un colegio / musical". Después continúa con estrofas dedicadas "A Gabriel Miró", "Corpus de Oleza", "Mayo. Mañana a medias", "Leyendo" y "Ángelus". Según el tono poético, parecen versos muy de la órbita del Miguel Hernández de su primera etapa, influido por Gabriel Miró y Rubén Darío.

El 20 de junio de 1931 se publicaron en la prensa provincial las bases del concurso para decidir el artista que realice el busto de Miró. El día 22 el Comité Pro-Homenaje cursa una instancia al Ayuntamiento de Orihuela para

\footnotetext{
28 “Oleza a Gabriel Miró. Dos conferencias de los hermanos Sijé", Revista del Instituto de Estudios Alicantinos, 27 (mayo-agosto 1979), pp. 243-258.

29 "Miguel Hernández en el marco geográfico y cultural de Orihuela", Revista del Instituto de Estudios Alicantinos, 22 (septiembre-diciembre 1977), p. 19 y ss.

30 "La opinión de Ramón Sijé sobre Francisco Salzillo (Notas de asalto a dos estéticas levantinas)", Monteagudo, 83 (1983), p. 10.
} 
solicitar la compra del busto y que el nombre de Gabriel Miró figure en una de las calles de la ciudad. Al día siguiente, el 23, se da a conocer en Orihuela una doble hoja en papel amarillo que empieza "Desagravio y recuerdo...". Dos meses más tarde, el 2 de agosto, se anuncia el fallo del concurso en Diario de Alicante. El jurado estaba compuesto por José M. ${ }^{a}$ Ballesteros, José Ma Pina Brotóns, Augusto Pescador, Miguel Hernández, el pintor Rodríguez y Ramón Sijé. Éstos son algunos párrafos del texto publicado: ${ }^{31}$

Coincidimos todos en el simbolismo de ese busto tan triste, de ese Gabriel Miró resucitado, obra de un escultor, áspero y joven, que se llama José Seiquer Zanón, que tendrá un gran porvenir, y que es de Murcia, de donde era María Fulgencia, aquella muchacha que quiso comprar el Ángel de Salcillo. El busto de Seiquer es admirablemente sencillo y en medio de su tristeza, sencillamente arrogante, he creído ver en él, la juventud de don Diego, el nómada que fue alcalde de Jijona. Allá, más en la oscuridad el busto de Aparicio, un muchacho que vive junto a un viejo teatro, en la Corredera, calle típica de Oleza y el busto de Pérez León, que estudia en San Fernando.

Orihuela se convertía de este modo en la primera ciudad en erigir públicamente un busto a Miró.

La Universidad Popular de Cartagena organizó una semana de homenaje a Miró, del 24 al 30 de septiembre, y Sijé fue invitado por Antonio Oliver Belmás en carta fechada el 14 de septiembre a ofrecer, el día 30, una conferencia, Oleza, pasional natividad estética de Gabriel Miró, publicada en $1990^{32}$ gracias a los buenos oficios de Sáez Fernández y la ayuda imprescindible de Ramón Pérez Álvarez en la localización de los ejemplares del diario cartagenero República, de los días 18, 19, 20, 21, 22, 24, 25, 26 y 27 de septiembre, que recogieron en su integridad dicha conferencia sijeniana. El día 29 el también diario cartagenero El Porvenir publicó el guión de la conferencia. La noticia de la conferencia sijeniana apareció el mismo 30 en La Tierra, y el 27 y 29 de septiembre y 1 de octubre en El Porvenir, el 26 de septiembre y 1 de octubre en República. José Rodríguez Cánovas ${ }^{33}$ transcribe el comunicado que la Universidad Popular

\footnotetext{
${ }^{31}$ J.A. Sáez Fernández, “Desagravio y recuerdo: gestación de un magno homenaje oriolano a la memoria de Gabriel Miró", Canfali Vega Baja (Orihuela) (6-X-1982), pp. 8-9.

32 Oleza, pasional natividad estética de Gabriel Miró, edición y estudio preliminar a cargo de José Antonio Sáez Fernández, Albox, Batarro, 1990.

${ }^{33}$ Antonio Oliver Belmás y la Universidad Popular de Cartagena, Cartagena, Imprenta Molegar, 1971, pp. $43-44$.
} 
cartagenera emitió como respuesta a la invitación cursada por Sijé para los actos del día 2 de octubre:

Conociendo la Universidad Popular el homenaje que la ciudad de Orihuela va a rendir al ilustre y malogrado escritor levantino, gloria de las letras españolas, Gabriel Miró, organiza una excursión para el día 2 de octubre con el fin de asistir a la inauguración del monumento que Orihuela dedica a su autor. Mas no estando la personalidad de Miró muy difundida entre nosotros, esta excursión de la Universidad Popular irá precedida de unas conferencias informativas que, fuera de curso y eminentes con este motivo, pronunciarán conocidos amigos de Miró en la cátedra de nuestra Universidad Popular. Ramón Sijé y José Rodríguez Cánovas hablarán respectivamente de Orihuela en la obra mironiana y de la novela en Miró. Mañana daremos guiones y demás detalles de estos actos de honda espiritualidad, a los que se invita a los afiliados a la Universidad y a cuantas personas amantes de la cultura deseen asistir a ellos.

Sijé participó el viernes 30 de septiembre, como ha sido comentado, y Rodríguez Cánovas el sábado 1 de octubre con la conferencia "Panorama de la novela española; luz mediterránea; paisajes, días y gentes".

Para la ocasión, fue publicada, en número único, la revista El Clamor de la Verdad. Cuaderno de Oleza consagrado al poeta Gabriel Miró (reeditado en facsímil en 1979), cuyo título nos recuerda evidentes resonancias mironianas. Colaboraron, aparte de Ramón Sijé, María Cegarra, Carmen Conde, Antonio Oliver Belmás, José M. ${ }^{a}$ Ballesteros (Premio Luca de Tena, de la Asociación de la Prensa de Alicante, en 1932 por su artículo “Orihuela y Gabriel Miró”), José M. a Pina Brotóns, Miguel Hernández, Carlos Martínez-Barbeito, Julio Bernácer y Raimundo de los Reyes. Se leyó el siguiente texto:

Orihuela se apresta, por fin, a rendir fervoroso homenaje al gran Gabriel Miró, que poetizó, en características y entrañables páginas, su existencia real y sus hombres representativos. Orihuela, convertida en "Oleza" por obra y gracia de la intuición comprensiva del estilista levantino, adviene al campo de la literatura española con justificado título, con máxima jerarquía de ciudad literaria.

Una delegación de la Universidad Popular de Cartagena, con Oliver Belmás y Carmen Conde a la cabeza, pero también acompañados de María Cegarra, acudió al acto celebrado en Orihuela aquel luminoso primer domingo de octubre de 1932. Carmen Conde nos ha dejado testimonio de aquella inolvidable jornada en la citada conferencia: 


\begin{abstract}
Algunos años después volví a ella ["Oleza”] cuando un grupo de muchachos inolvidables levantó el monumento a Gabriel Miró. Terminado el acto oficial vinimos, unos pocos, a una casa que tenía balcones al río, a este río limoso y oscuro que es más Orihuela que sus propias calles. No sé si aquella casa era un casino o un círculo de Bellas Artes; lo que sí sé es que en aquellos balcones conocí personalmente a un muchacho de azules y dilatados ojos que me enseñaba muchas hojas llenas de versos suyos. Era Miguel Hernández y sus poemas los que más tarde reuniría Perito en lunas. El río, debajo de mis ojos; a mi lado, María Cegarra; enfrente, Miguel. ¡La poesía, Orihuela, el río....! ¡Qué alucinante e imborrable emoción la de aquel día!
\end{abstract}

Según Vicente Ramos, ${ }^{34}$ Marcelino Domingo no pudo desplazarse a Orihuela y por ello acudió Ernesto Giménez Caballero. La iniciativa de invitar al entonces director de La Gaceta Literaria no partió exclusivamente de Ramón Sijé sino del Comité. Además, la revista madrileña dedicó un número monográfico a Miró el 1 de junio de 1930. La admiración mironiana de Gecé estaba fuera de toda duda.

La relación de Ernesto Giménez Caballero con Sijé procedía de enero de 1932. Recordemos que ambos estudiaban Derecho en la Universidad de Murcia. En el archivo de Sijé se conservan 12 cartas del primero al segundo. Según Eutimio Martín, ${ }^{35}$ después del incidente provocado por Giménez Caballero aquel mismo día, consagrado a Miró, que se burló de la incipiente República, y que provocó las airadas protestas de, entre otros, Antonio Oliver Belmás, no había oposición ideológica por parte de Sijé a Giménez Caballero, sino "competencia". Del nacional-catolicismo del madrileño, a Sijé sólo le interesaba, según Martín," 36 "la dimensión teocrática". Lo que es un hecho es que a finales de 1932, y como consecuencia de la desagradable bronca provocada por Giménez Caballero, se enfría la amistad de Sijé con él (a pesar de que Gecé decidiera estudiar Derecho como alumno libre en Murcia), buena prueba de ello es que La Gaceta Literaria no figura, dos años después, entre las revistas con las que El Gallo Crisis mantenía intercambio, así como la siguiente mención al "inspector de alcantarillas" en el artículo "El 'AZAÑA' de Ernesto Giménez Caballero: Nueva Orestiada hispánica", en su sección "Flor fría a todos los otoños" del 18 de diciembre de 1932 en La

34 “Oleza a Gabriel Miró", Revista de Moros y Cristianos (Orihuela) (1980), s. p.

35 “Ramón Sijé-Miguel Hernández: una relación mitificada”, op. cit., p. 51.

${ }^{36}$ Ibidem, p. 51. 
Verdad: «Ernesto Giménez Caballero es un chulito; un mocito antieuropeo (...) un verbenero intelectual».

Lo que es un hecho es que Sijé no realizará ninguna gestión para ayudar a Giménez Caballero como candidato por Murcia en el bloque de la CEDA, según petición del madrileño en carta fechada el 10 de octubre de 1933. Siete días después, el 17 de octubre, Gecé confiesa a Sijé que si es necesario aliarse con el Diablo (CEDA), sólo importa el fin: "Se trata de vencerlos en sus propias trampas".

Gecé, en el prólogo que realizó a la novela Naranjos y limoneros, de José M. ${ }^{a}$ Ballesteros ${ }^{37}$ publicada en Madrid en 1935, recuerda, tres años después, los hechos:

Es natural que, cuando en plena 'Glorieta', rodeado de oficialidad política, de músicos municipales y de pueblo, me puse a hablar en camiseta azul y diciendo algunas verdades redondas, alguien iniciara un escándalo. Escándalo conscientemente provocado por mí para darme el gusto de cortarlo con aplausos y vítores apenas exalté lo que en Miró había de eterno y de clásico.

Cinco años después, el 30 de julio de 1937, en plena guerra, el madrileño escribe un artículo en la edición sevillana de $A b c$, "Símbolos de unidad. La camisa azul", en el que vuelve a recordar, a su manera, aquel domingo de octubre de 1932.

La siguiente consecuencia de la animadversión será un texto de Sijé, publicado en el primer número de la revista sijeniana, ${ }^{38}$ no incluido en la edición facsímil de la revista, en el que el pensador oriolano critica duramente la Falange. Cecilio Alonso ${ }^{39}$ supone que el ensayista "teme un fascismo funcionarista y tibio". Por su indudable interés lo transcribimos en su integridad.

OFICIALES de correos y telégrafos ocupan, ya, los puestos rectores del casi naciente fascismo hispánico. Quizá por su presunta psicología revolucionaria, por su pedantería técnica de funcionarios mimados. Fascismo, pues, funcionarista de abogados y marqueses que son diputados, de poetas que son catedráticos: "fascismo oficial de correos y telégrafos. Fascismo", por consiguiente, "partido", partido político y partido por el eje; fascismo que huele: a política sangrienta de alcantarilla. "El fascismo

\footnotetext{
${ }^{37}$ Texto recogido en Memorias completas de José $M^{a}$ Ballesteros, Madrid, Héroes, 1979, p. 198.

${ }^{38}$ Sección "Las Verdades como Puños", 1 (Corpus de 1934), p. 25.

39 "Fascismo, catolicismo y romanticismo en la obra de Ramón Sijé", Camp de l'arpa, 11 (mayo 1974), p. 30.
} 
es incompatible con la unidad de la razón". Recuérdense aquellas áureas palabras agustinianas: "La razón humana es una fuerza que conduce a la unidad". El fascismo tiene la razón de la fuerza, pero no la fuerza de la razón. Agota su propia capacidad creadora antes de llegar a la nación, cosa racional una, cosa real, una: "puño temeroso y amenazador". !Falange!..., bueno, falange; falangina y falangeta: un dedo. Para moldear el concepto de España se necesita todas las manos del alma.

Otra reseña no menos dura de Sijé fue la que realizó del libro de Giménez Caballero El Belén de Salzillo en Murcia. (Origen de los Nacimientos en España), aparecida en el número 2 de El Gallo Crisis, ${ }^{40}$ con el título "La novela del belén, o, el barroco temporal y el eterno barroco", en donde critica severamente el libro y la estética que subyace en el mismo.

Ya después de la guerra, Giménez Caballero insistirá en su versión de los hechos. En carta fechada en Madrid el 19 de marzo de 1954, dirigida a Concha Zardoya, ${ }^{41}$ afirmaba que ambos amigos [Ramón Sijé y Miguel Hernández] "fueron de los primeros falangistas" y que "los dos le saludaron con la mano abierta". En sus Memorias de un dictador, ${ }^{42}$ el heterodoxo fascista recordaba que "ya en 1931 [sic] y en Orihuela, ante el busto de Miró, con Ramón Sijé y Miguel Hernández, utilizamos camisas azules de algodón como color laboral y operario". No tengamos en demasiada cuenta la inclinación de Giménez Caballero en otorgar carné de fascista a todo aquel que ha conocido.

\section{ENSAYO}

A principios de 1933 decae la estrella 'giménezcaballerista' y se inicia la relación con Bergamín. Esto traerá consigo una progresiva evolución en su concepción literaria. Abandona, si bien no del todo, sus colaboraciones periodísticas y se centra en el ensayo, siempre entendido éste como comentario subjetivo y no crítico, producto de sus muy variadas y numerosas lecturas, que pretendía servir de guía en las procelosas corrientes del pensamiento de aquellos primeros años treinta.

\footnotetext{
${ }^{40}$ Virgen de Agosto de 1934, pp. 28-31.

${ }^{41}$ Miguel Hernández (1910-1942). Vida y obra. Bibliografía. Antología, New York, Hispanic Institute in the United States, 1955, p. 16.

42 Barcelona, Planeta, 1979, p. 208.
} 
La primera carta conocida del fundador de Cruz y Raya a Sijé está fechada el 1 de septiembre de 1933, y bien pudo interceder, de nuevo, Juan Guerrero Ruiz.

En marzo de 1933 Sijé concluye "El héroe como concepto", su primer ensayo, entendido como tal, más extenso que los artículos periodísticos, y publicado en una revista literaria, en el número 4 de la gaditana $I s l a,{ }^{43} \mathrm{y}$ dedicado "A José Bergamín, por su cruz, por mi espada de cruz y en cruz". Se refiere al héroe cristiano, al estilo de Baltasar Gracián. Recordemos, por otro lado, que Miguel Hernández en su escasamente conocido artículo dedicado a Sijé, ${ }^{44}$ recuerda que Sijé

fue un héroe y resistió mientras pudo a pie firme las violentas tempestades que se organizaron y chocaron de continuo entre su corazón y su cerebro. Pocos hombres han vivido una vida interior tan intensa y sangrientamente volcánica como Ramón Sijé.

En los primeros años treinta el concepto de héroe (si bien desde perspectivas diversas) estaba en el ambiente, por ejemplo en las biografías, revistas (una de Manuel Altolaguirre llevó este mismo título, Héroe, y el impresor malagueño es también autor de una biografía de Garcilaso de la Vega, muy popular, publicada en 1933), etc. Por su parte, se da la casualidad de que el primer artículo conocido de Sijé, escrito a los doce años, llevara el título de "España, la de las gestas heroicas", publicado, precisamente, como ha sido mencionado, en el número 41 de la revista madrileña Héroes el 31 de marzo de 1926, destinado a un concurso para niños menores de diecisiete años. Otro trabajo, muy interesante, que se refiere al héroe es "Del antihéroe (Revolución y alzamiento)", publicado en Diario de Alicante el 20 de agosto de 1932, en el que critica al general Sanjurjo y lo tilda de "anticivil, antimilitar, antipatriota", así como pone en evidencia el falso concepto del honor del militar golpista. Quizás este último artículo pueda interesar a quienes ven en Sijé un filofascista irredento. Los generales Sanjurjo y García de la Herrán intentaron un golpe de Estado el 10 de agosto de 1932, conocido como la "sanjurjada", que fracasó estrepitosamente.

\footnotetext{
${ }^{43}$ Op. cit., pp. [89-92].

44 "Un acto en memoria de Ramón Sijé. Unas cuartillas de Miguel Hernández", publicado con este título en El Sol, el 17 de abril de 1936, y en La Verdad de Murcia el 7 de mayo del mismo año con el rótulo "Letras evocando a Sijé. En el ambiente de Orihuela".
} 
El primer ensayo de Sijé publicado en la revista de Bergamín, Cruz y Raya, fue "San Juan de la Cruz (Selección y notas)", en las páginas 85-100 del número 9, de diciembre de ese mismo año de 1933. En esas navidades, visita en Madrid al nuevo amigo y queda encantado con él.

"El golpe de pecho o de cómo no es lícito derribar al tirano", publicado en las páginas 26-42 del número 19 de la mencionada revista de Bergamín, correspondiente a octubre de 1934, contiene interesantes afirmaciones, como la siguiente: "El que justifica la muerte del tirano justifica la muerte y el suicidio del hombre, y en definitiva, su propia muerte airada y su propio suicidio". Más adelante, sostiene que "el poder mismo derribará al tirano".

Particularmente este ensayo, pero también otros, traerá como consecuencia una catarata de artículos, especialmente de críticos hernandianos, preocupados por cuanto ello pudo influir en la trayectoria vital y literaria de Miguel Hernández, y que tacharon a Sijé de filofascista o fascista sin más. Quizás convenga aquí y ahora aclarar que el ensayista no justifica la tiranía, de hecho Sijée ${ }^{45}$ se definió como "demócrata complaciente". Un ejemplo de esta clase de estudiosos es Concha Zardoya, ${ }^{46}$ que, en su bienintencionado y mencionado libro, sostiene:

Parece ser que Ramón Sijé, por vía del catolicismo, se inclinaba a coquetear con aquellas ideas [fascistas o filofascistas]. Y aún hay informantes que han osado afirmar que también Miguel Hernández, contagiado por su amigo, no sólo las toleraba, sino que las suscribía.

Otros investigadores que destacan en esta línea crítica son Agustín Sánchez Vidal, ${ }^{47}$ Jesucristo Riquelme, ${ }^{48}$ Eutimio Martín," ${ }^{49}$ que lo califica de "fascista militante" y que afirma que lo único que unía a Sijé y Hernández era su conciencia de su valía intelectual y su deseo de conseguir el estatus social buscado, y Robert Marrast, ${ }^{50}$ en relación con el estudio sijeniano sobre el romanticismo.

\footnotetext{
45 “El analfabetismo, admirable amigo de la cultura (Nueva venida de Zarathustra)", publicado en Diario de Alicante el 6 de septiembre de 1932, p. 1.

${ }^{46}$ Op. cit., n. ${ }^{\circ} 38$, p. 15.

${ }^{47}$ Miguel Hernández en la encrucijada, Madrid, Cuadernos para el Diálogo, 1976, p. 11 y ss.

48 "Causas de una producción artística: Quien te ha visto y quien te ve de M. Hernández", Revista del Instituto de Estudios Alicantinos, 37 (septiembre-diciembre 1982), pp. [175]-191.

49 "Ramón Sijé-Miguel Hernández: una relación mitificada", op. cit., p. 45.

50 "Ramón Sijé y el romanticismo o el arte del galimatías reaccionario", en Serge Salaün-Javier Pérez Bazo (eds.), Miguel Hernández: Tradiciones y Vanguardias, Alicante, Instituto de Cultura Juan Gil-Albert, 1996, pp. 51-57.
} 
Martín utiliza, en mi opinión, torticeramente unas afirmaciones de Tomás López Galindo ${ }^{51}$ claramente partidistas y no ajustadas a la realidad de Sijé, recogidas en el artículo "Idea y sentimiento, mutuamente controlados", del abogado oriolano: "Aceptó sincera, auténtica y honradamente, las teorías del Estado totalitario", sin copiar que ante la conciencia de una nueva guerra, Sijé tenía listo un documento titulado "Llamamiento a los escritores públicos, para la propagación apostólica de la paz", en el que, según el propio López Galindo, "se percibe claramente este cambio de sensibilidad y por ende de doctrina". Eutimio Martín ${ }^{52}$ reconoce que su prematura muerte "nos impide concluir en la confirmación o invalidación de la actitud teórica y prácticamente profascista", aunque también afirma, ${ }^{53}$ que "Miguel Hernández militó en las filas del fascismo español. Su mentor fue Ramón Sijé, que le tenía asignado a perpetuidad el papel de poeta campesino del imperio».

También es cierto que un coetáneo de Sijé, José M. ${ }^{a}$ Olmos, ${ }^{54}$ afirmó, en el número 41 de la citada revista oriolana Acción, dedicado casi por entero a Sijé, de fecha 30 de diciembre de 1935, que el pequeño filósofo "ha visto, porque lo ha pensado, a la nueva España (...) no ha visto la meta estando tan cerca de ella". Ello no significa nada. Endosar a un difunto adscripción partidista según intereses espurios es algo censurable, tanto si miramos a izquierda como a derecha. Ramón de Basterra (1888-1928) también tuvo que soportar desde su tumba cómo los falangistas le encumbraron como precursor del nuevo Estado. Sin embargo, Vicente Ramos ${ }^{55}$ afirma que Sijé “siempre mantuvo una postura democrática", y no encontró "ningún texto (...) que pruebe la más leve inclinación a favor de las teorías fascistas". Por su parte, Cecilio Alonso, ${ }^{56}$ en un conocido artículo, escrito con escasa imparcialidad, defiende que los textos "en apariencia socializantes" de Sijé son, en su significado profundo, "ingenuamente demagógicos".

El 2 de enero del crucial año de 1935, el carlista Víctor Pradera le dirige una circular, del Consejo Superior de Cultura Tradicionalista, perteneciente a Comunión Tradicionalista, en la que anuncia la creación de la revista Tradición,

\footnotetext{
${ }^{51}$ Acción, 41 (30-XII-1935), p. 3.

${ }^{52}$ Ibidem, p. 52.

53 "Ramón Sijé-Miguel Hernández: una relación mitificada", op. cit., p. 53.

54 "Un aspecto de Sijé", p. 2.

${ }_{55}^{5}$ Miguel Hernández, Madrid, Gredos, 1973, pp. 75-76.

56 “Fascismo, catolicismo y romanticismo en la obra de Ramón Sijé”, op. cit., p. 30.
} 
dentro de una campaña promovida por Acción Española "en pro y defensa de los fundamentos espirituales de la Hispanidad”. El texto dice:

Por todo lo arriba expuesto nos dirigimos a Ud. para solicitar nos ayude con su suscripción. Ayuda ésta que, conocidos sus ideales y dada la importancia de la empresa, esperamos no habrá de faltarnos.

No existe constancia de que Sijé mantuviera relación alguna de cualquier tipo con dicha organización.

Jesús Poveda, ${ }^{57}$ nada sospechoso de ser derechista, recordaba en 1990 que aunque Sijé y él tuvieran ideas políticas distintas, ya en plena República, "jamás llevaba éstas a una ruptura con sus amigos o conocidos".

Además, la conocida y sectaria opinión de Neruda, dirigida en carta a Miguel Hernández, sobre la revista oriolana también ha tenido mucho que ver en esa obcecada y manida tendencia de la crítica de endosar el marbete de fascista o filofascista a Sijé: "demasiado olor a iglesia, ahogado en incienso", y que desprendía "ese tufo sotánico-satánico".

Si nos centramos en la relación entre Bergamín y Sijé, evidentemente existen discrepancias ideológicas entre ellos por el aire revolucionario de izquierdas de la revista dirigida por el primero. Sáez Fernández ${ }^{58}$ las ha analizado en un valioso artículo.

Sáez Fernández recuerda que Sijé criticó el libro La cabeza a pájaros publicado por el propio Bergamín en 1933, en las ediciones de Cruz y Raya. En la reseña, aparecida con el título "Péndulo y carbonería" en el número 1 de El Gallo Crisis, ${ }^{59}$ Sijé recrimina al amigo sus juegos con su dolor de pensamiento: «juega para salvarse. Juega con la fe, el aburrimiento, la frivolidad, la música y los gallos 'republicanos'. Juega a juegos de vida o muerte: juegos de plomo».

El mismo estudioso sijeniano, ${ }^{60}$ afirma que la mayor influencia de Bergamín en Sijé radica en el estilo, "que es el conceptismo de Quevedo. Así podría hablarse del escritor oriolano como de un "conceptista católico'". También El Gallo Crisis acusó una cierta influencia de Cruz y Raya en su estructuración: las "Antologías" y "Verdades como Puños" son el correlato

\footnotetext{
57 "Amistad con Ramón Sijé", Batarro (Albox), 2 (enero-abril 1990), p. 22.

58 "Ramón Sijé y José Bergamín: amistad y discrepancias", Anales del Colegio Universitario de Almería. Letras (Almería), vol. V (1983-1984), pp. 7-13.

${ }^{59}$ Corpus de 1934, pp. 31-32.

${ }^{60}$ Op.cit., p. 13, n. ${ }^{\circ} 1$.
} 
sijeniano de los bergaminescos "Cristal del Tiempo" y "Criba", así como la presentación de textos con notas o comentarios, orientados hacia un punto concreto, proceden de la revista madrileña.

\section{El Gallo Crisis}

Las continuas visitas de Sijé, José M. ${ }^{a}$ Quílez y Sanz, Tomás López Galindo, Juan Bellod Salmerón, y de los profesores Juan Colom y Jesús Alda Tesán al Padre Buenaventura de Puzol en el convento de los Capuchinos, trajeron como consecuencia la creación de la revista. El subtítulo de El Gallo Crisis era "Libertad y tiranía". En el número 5 de la revista Isla, publicado en 1934, se anuncia la inminente salida de la revista oriolana. Pues bien, en dicho suelto, se transcribe parte del "índice de tesis", que puede resultar interesante transcribir:

¡Viva España! en su Caridad, en su Patria, en su Concepto. Por la libertad y la tiranía, que es la madre y la hija de la libertad. ¡Viva y muera! juramos con la mano de España, mano que puede sembrarse - como se sembró la izquierda - en nuevo, nunca soñado Lepanto; manos de santiguarse por la libertad, de escribir por la tiranía de los cuerpos y de las sombras. Al servicio de España en crisis y en crisálida.

El consejo de redacción estaba compuesto por los citados Jesús Alda Tesán, Juan Colom, Tomás López Galindo, José María Quílez y Sanz y Fray Buenaventura de Puzol, y la finalidad del mismo era aglutinar culturalmente diversas sensibilidades, no todas coincidentes entre sí en lo ideológico. Sijé asumió responsabilidades de director, y Juan Bellod Salmerón de secretario. El director supo mantenerse por encima de los distintos grupúsculos culturales que convivían en la ciudad. Fueron publicados, como se sabe, seis números, dos de ellos dobles: n. ${ }^{\circ} 1$ (Corpus de 1934), n. ${ }^{\circ} 2$ (Virgen de Agosto de 1934), n. ${ }^{\circ}$ 3-4 (San Juan de Otoño de 1934), n. ${ }^{\circ}$ 5-6 (Sto. Tomás de la Primavera-Pascua de Pentecostés 1935). Muñoz Garrigós dedicó, como ha sido comentado, o aparte de su memoria de licenciatura, varios trabajos a la revista, que suponen el acercamiento más interesante y objetivo a la misma.

La revista pretendió ser el guía intelectual de los católicos en un momento histórico crucial para éstos. La búsqueda de directrices intelectuales la asemeja a Revista de Occidente. Critica la pasividad de la generación del 98 por no hallar soluciones a la profunda crisis que azotó a España después 
del desastre de 1898. Además de suponer un hito en el pensamiento español de entreguerras, el gallo que ilustra la portada simboliza una revisión de las costumbres aceptadas, como el resto de las viñetas de Francisco de Díe y el perfeccionamiento de los lectores, tanto desde el punto de vista espiritual como civil.

La revista se identifica con la personalidad de su director, con el inquebrantable apoyo de quienes formaban parte de la redacción. Casi una semana después de su muerte, José M. ${ }^{a}$ Quílez, ${ }^{61}$ mecenas de la publicación periódica, afirmó: “Sus seis números publicados han sido como los seis tomos de su obra personal, exclusiva e ingente". Otro colaborador de la revista, Jesús Alda Tesán, ${ }^{62}$ único profesional literato de la revista, afirmó que Sijé fue "uno de los hombres más auténticamente consumido por la sed espiritual".

Según Ana M. Reig Sempere, ${ }^{63}$ en un ejemplar de la revista que Sijé dedicó a su entonces novia Josefina Fenoll, podemos leer: "A mi nena, este primer número de una revista que soy yo mismo". La dedicatoria del último no deja lugar a dudas del esfuerzo físico e intelectual que le desgastó: "Muchos dolores me suponen esta obra, que parece va a terminar con estas páginas. Tú eres el gozo y el mío".

La revista resume el ideario de Sijé: identifica España con el Imperio, éste con Castilla, la salvación de España con el catolicismo; si el país fue grande en el Siglo de Oro, cuando fue Imperial y Católico, es necesario restituir ambas características. Así, la estética conceptista de aquel tiempo se recupera (octavas reales, décimas, sonetos...) y, sobre todo, el auto sacramental. Sijé influirá en la concepción 'clásica' del auto, también ideológica de un nostálgico de tiempos pasados, en la consecución de un sistema estético coherente con lecturas de Góngora, Calderón de la Barca, Lope de Vega, Quevedo, San Juan de la Cruz, etc. En aquel tiempo, no lo olvidemos, fluctuaban mucho las concepciones políticas o ideológicas. Pocos años después será necesario tomar posiciones, y Ramón Sijé no tomó ninguna clara antes de morir.

En la carta-circular preparada para anunciar la inminente salida de la revista, Sijé la define como "de tipo doctrinal y polémico, destinada a todas aquellas personas que hacen de la cultura su íntimo problema diario".

\footnotetext{
61 “'Ramón Sijé' ha muerto”, Acción, 41 (30-XII-1935), p. 1.

62 J. Guillén García- J. Muñoz Garrigós, Antología de Escritores Oriolanos, Orihuela, Publicaciones del Excmo. Ayuntamiento de Orihuela, 1974, p. 194.

${ }^{63}$ La generación del 30 en Orihuela, Alicante, Instituto de Estudios Alicantinos, 1981, p. 39.
} 
La revista se enviaba gratuitamente a quienes no disponían de medios económicos pero deseaban recibirla, según consta en los créditos de los números 3 y 4 (San Juan de Otoño de 1934) y 5-6 (Sto. Tomás de la PrimaveraPascua de Pentecostés 1935). De 15.000 habitantes que tenía Orihuela, sólo se contabilizaban treinta posibles suscriptores. No llevaba publicidad alguna, aunque se tomó en consideración al principio tal propuesta. José María Quílez y Sanz sufragó todos los costes de la publicación. El precio del número sencillo era de dos pesetas, y el del doble, cuatro pesetas. Por cierto, en la edición facsímil no figura en los sumarios correspondientes el lugar en donde se imprimía la revista: Editorial La Verdad, S.A., de Murcia, seguramente con la amistad de Raimundo de los Reyes de por medio. En los números originales sí se consigna este dato. Recordemos que, como ha sido mencionado, en el número 6 de Destellos, del 31 de enero de 1931, Sijé destina la primera página de la revista a cuatro poemas del autor murciano, bajo el título "Cancionero".

El Gallo Crisis no tenía sentimiento localista, ni fue una revista de corte literario sino de pensamiento y ensayo. La publicación dio a conocer a Miguel Hernández y le facilitó resortes técnicos que le fueron tan importantes en su trayectoria poética. Sin embargo, más allá de las colaboraciones hernandianas, merece, en mi opinión, una lectura más justa de la que se le ha venido dando hasta ahora.

De hecho, la revista estaba al corriente de las líneas renovadoras de la Iglesia: la del humanismo cristiano y la del movimiento guardinista y de Jacques Maritain, el existencialismo cristiano de Meter Wust y el neo-tomismo con un elevado componente poético que Cecilio Alonso ${ }^{64}$ califica de servir como un "instrumento edulcorante que ilustraba las tesis doctrinales del director". Según Sijé, las virtudes que caracterizan al buen católico, al de su tiempo, son: el ascetismo, la verdad, la humildad y la pureza de su espíritu. La revista sentía la necesidad de autentificar la fe a nivel también colectivo, no sólo individual. Atacó la apatía de los católicos y se anticipa al Concilio Vaticano II en rechazar la importancia de la apariencia externa, en beneficio de una fe vivida auténticamente. Sijé fue muy crítico con la Iglesia oficial, lo que le supuso su indiferencia y la de los jesuitas, y con el capitalismo.

\footnotetext{
${ }^{64}$ Op. cit., p. 28.
} 
Aún así, Jesucristo Riquelme, ${ }^{65}$ afirma que aparecen "símbolos falangistas" en la ilustración de Francisco de Díe que acompaña al poema hernandiano "PROFECÍA-sobre el campesino" ${ }^{66}$ racimo de uvas y tres espigas cruzadas atados por un lazo que "recuerda", según Riquelme, al yugo y las flechas falangistas.

Según José Guillén García y José Muñoz Garrigós, ${ }^{67}$ "no es tan clara ni definida la postura política de Sijé", aunque considera que Sijé "no deseaba (...) mantener el orden establecido, fundamentalmente en lo social y en lo religioso". Algunos ejemplos: en la sección habitual "Las Verdades como Puños" y en "Decadencia de los ojos del sacerdote" y "Obrero parado de no vivir"; 68 "El veraneo del hambre" y "Anemia del púlpito y del confesionario"; 69 "El arte de comulgar", "La concepción etérea del dinero", "Cuatro caballeros de frac o cuatro granujas sin tacha"; 70 "El tratado de guerra de Versalles", y "Amonestaciones al sacerdote sobre la pérdida de la caridad viva", ${ }^{71}$ suponen la crítica de aquellos vicios de los católicos que merecen ser desterrados para aspirar, no sólo a la Gloria celestial, sino a la de aquí y ahora, con los semejantes. Sijé defendía un Estado teocrático, algo totalmente utópico y ucrónico en los años treinta. Sin embargo, no hay duda de que para Sijé el poder parte del pueblo, aunque al final se encuentre Dios, sin que ello signifique que el poder político emane de Dios. Defiende una justicia distributiva, y con ello, el socialismo católico. Es evidente su inclinación al proletariado de las derechas por los problemas sociales. ${ }^{72}$

El notario José M. ${ }^{a}$ Quílez y Sanz es autor de un raro suplemento exento del número 2 de la revista, ${ }^{73}$ de ocho páginas, Pasión y compasión en el concepto de propiedad, que se vendía al precio de una peseta, y que hacía el número 1 de la Biblioteca de El Gallo Crisis, 'El Perfume Intenso'. Gracias a los fondos de la Biblioteca Gabriel Miró, de Alicante, hemos tenido acceso a este suplemento, que Muñoz Garrigós no pudo consultar, y en el que se incluye la siguiente presentación, desconocida hasta ahora:

\footnotetext{
65 "Causas de una producción artística: Quien te ha visto y quien te ve de M. Hernández", op. cit., p. 185.

${ }^{66} 1$ (Corpus de 1934), p.14.

${ }^{67}$ Antología de Escritores Oriolanos, op. cit., pp. 196-197.

${ }^{68} 1$ (Corpus de 1934), pp. 24-25.

${ }^{69} 2$ (Virgen de Agosto de 1934), pp. 24-27.

70 3-4 (San Juan de Otoño de 1934), pp. 24-29.

${ }^{71}$ 5-6 (Sto. Tomás de la Primavera-Pascua de Pentecostés 1935), pp. 33-41.

72 "La primavera de las hipotecas y el otoño de los labradores", 5-6 (Sto. Tomás de la PrimaveraPascua de Pentecostés 1935), pp. 6-14.

${ }^{73}$ Virgen de Agosto de 1934.
} 
Una biblioteca es un sistema histórico de polémicas: el 'se continuará' eterno del pensamiento. Ideal o tipo de biblioteca humana -por inhumanizadora, es decir, por cristiana- es el índice polémico que representa 'el Catecismo': como enciclopedia del cristianismo: como conclusión dogmática de las contiendas eternas. El Gallo Crisis recogerá en esta biblioteca catecismal, en estos cuadernos mínimos, 'el perfume intenso' que, a través de los siglos, esparce cada polémica: cada concepto: cada pilar básico: 'en vital crisis'.

En el número $2{ }^{74}$ Sijé expresa sus quejas por el escaso eco producido. En uno de los "Picotazos", 75 se afirma:

El Gallo Crisis no cambia, no vende, no se quita la corona sangrienta de su cresta. Se explica fácilmente que los escritores oficiales de Madrid - que le conocen - estén en contra de El Gallo Crisis. Pero él sigue ahogando sus lamentos y articulando sus gritos".

En carta a Sijé fechada el 19 de abril de 1934, Gecé le reprochará que

Gallo Crisis va a ser una revista más minoritaria, gongorista, conceptista, con aire bergaminesco de cara y cruz. Lo siento. Ustedes (...) debían ir por un sendero más claro, rotundo, popular, ardiente, inteligible a las masas. Pero no es así (...) Una cosa más franciscana y menos jesuita se necesita hoy (...) Hay que dejar en literatura la acción indirecta, ese parlamentarismo del circunloquio, la perífrasis y el arabesco.

En 1934 Miguel Hernández intenta colocar la revista en Madrid, y Neruda le dice: "Siento decirle que no me gusta El Gallo Crisis. Le hallo demasiado olor a iglesia, ahogado en incienso". Miguel Hernández, en carta fechada en junio de 1935 a Juan Guerrero Ruiz, califica la revista de Sijé de "exacerbada y triste revista", y confiesa sentirse "harto y arrepentido de haber hecho cosas al servicio de Dios y de la tontería católica".

El 7 de diciembre de 1934, en carta desde Barcelona, Enrique de Juan ofrece su colaboración poética a Sijé, ya que se ha enterado por el número de verano de la revista zaragozana Noreste, que existe una revista católica "de corte nuevo". Alfredo Marqueríe y José María Pemán alaban la revista. La Verdad, de Murcia, también se interesará por ella, como Diari de Tarragona, que el 9 de enero de 1935, el 4 de julio de ese año, y en otras ocasiones, resumirá los sumarios de la revista

\footnotetext{
${ }^{74}$ Virgen de agosto de 1934, p. 23.

${ }^{75}$ 3-4 (San Juan de Otoño de 1934), p. 23.
} 
oriolana. La revista gaditana Isla, la albaceteña Ágora y la aragonesa, ya citada, Noreste igualmente prestarán atención a los contenidos de la revista oriolana.

Resulta también muy interesante observar las revistas y libros referenciados o comentados porque nos dan la medida de los intercambios e intereses que tenía Sijé y quienes con él apoyaron la revista oriolana. Entre las revistas recibidas, destacan tan variadas como las madrileñas Cruz y Raya, Frente Literario, Eco, Revista de las Españas, Religión y Cultura, Acción Española, Literatura y Tierra Firme. También las mencionadas Isla (Cádiz) y Ágora (Albacete), Azor (Barcelona), Revista del Ateneo de Jerez, Atalaya (Lesaca), Hojas de Poesía (Sevilla), Ciprés (Burgos), Nueva Cultura (Valencia) y Revista Hispánica Moderna. La panorámica es, ciertamente, algo sorprendente, pues son, en general, de gran calidad y en las que colaboran figuras de primer orden. En este sentido, estaban muy enterados de lo mejor que se publicaba.

En cuanto a los libros reseñados o simplemente citados (la alusión denota algo de interés), también son relevantes: Verde voz (Félix Ros), Señorita del mar (José M. ${ }^{a}$ Pemán), La cabeza a pájaros (José Bergamín) y Poesía, 19241930 (Rafael Alberti); pero también Pimpín (Gaspar Gracián), 33 canciones (Álvaro Arauz), Tránsito (Raimundo de los Reyes), Nebulosas (Dictinio de Castillo-Elejabeytia), Identidad (Rafael Laffón), Una lágrima sobre la gaceta (del citado Félix Ros) y El aviso de escarmentados del año que acaba y Escarmiento de avisados para el que empieza de 1935 (Cruz y Raya). La nómina es pequeña, pero mayoritariamente encuadrada en la "joven literatura". Así, pues, el criterio selectivo no es sectario, ni mucho menos, sino abierto y escorado hacia la poesía innovadora. Vale decir también que los colaboradores "externos" son asimismo reveladores: Luis Felipe Vivanco, Luis Rosales y Félix Ros, caracterizados por una tonalidad clasicista. ${ }^{76}$

Otro tanto puede decirse de la correspondencia conservada de este periodo, de la que destacamos, entre otros, a remitentes como Juan Ramón Jiménez, los hermanos Alfonso y Francisco Rodríguez Aldave, que desde Lesaca (Navarra) dirigían la revista Atalaya, los citados José Bergamín, Pedro Pérez-Clotet, Félix Ros, Rafael Laffón y Adriano del Valle.

En carta del 14 de agosto de 1935 a Manuel de Falla, Sijé resume el ideario de la revista: «quiero que vea en El Gallo Crisis una voluntad de

\footnotetext{
${ }^{76}$ Joaquín Juan Penalva es autor de un interesante artículo sobre este asunto: "Tres poetas del 36 en El Gallo Crisis: Félix Ros, Luis Felipe Vivanco y Luis Rosales", Alquibla (Orihuela), 8 (2002), pp. 553-572.
} 
hombría, humildad, cólera y cristianismo (...) Mi revista ha querido conciliar el ideal del buen hombre con el ideal del buen escritor». En esa misma carta, se sincera con el músico granadino y le informa que «mi amigo y enemigo José Bergamín ha dicho en Madrid que El Gallo Crisis es el tumor que le ha salido a Cruz y Raya».

\section{Ramón Sijé - Miguel Hernández}

La relación de amistad y de pupilaje intelectual de Sijé sobre Miguel Hernández ha hecho correr ríos de tinta entre algunos conspicuos críticos, como hemos tenido ocasión de advertir anteriormente. Pese a quien pese, una entrañable amistad unió a los dos escritores oriolanos, por encima de ideologías y de la distancia. En este punto, traeremos a colación los materiales más interesantes relacionados con Miguel Hernández, procedentes del archivo de Ramón Sijé, toda vez que José Muñoz Garrigós ha aclarado suficientemente dicha amistad.

Ramón Sijé y Miguel Hernández coincidieron en el Colegio de Santo Domingo. Se conserva una fotografía en la que ambos, acompañados de otros compañeros, aparecen sentados en la típica imagen de recuerdo. Se realizó con motivo de la Promulgación de Dignidades el 23 de diciembre de 1923.

En este sentido, hemos localizado un importante documento, compuesto de tres hojas manuscritas, titulado "Miguel Hernández: Un retrato y tres paréntesis", que se supone es un borrador con apuntes destinados a una conferencia, que bien podría ser la mencionada anteriormente. No ha sido publicado en las bibliografías relacionadas con Ramón Sijé y Miguel Hernández. En el primer "paréntesis", Sijé afirma que Hernández "no es un espontáneo". En el "retrato", el ensayista recuerda que conoció al poeta en aquellos "tiempos borrosos del colegio", refiriéndose al Colegio de Santo Domingo. Luego, cuando Sijé contaba quince años y ejercía de redactor jefe de la revista Voluntad, el "pastor poeta" como le rememora, recibe palabras de aliento de José María Ballesteros desde las páginas de la mencionada revista. La "franca amistad" se refuerza con las colaboraciones de ambos en Destellos y la común amistad con José María Ballesteros, escritor que asumía en la práctica el título de maestro de toda la generación a la que, según algunos críticos como Vicente Ramos, José Muñoz Garrigós, Ana M. Reig Sempere y José Antonio Sáez Fernández, pertenecían Sijé y Hernández. Entonces, como sostiene 
Sijé, "El poeta viene a mi casa. Intercambio de lecturas y conversaciones". También dice de él que "es un tesoro oculto y raro: un poeta tímido". En un párrafo esclarecedor Sijé apunta lo siguiente: "Aparición de Miró y Juan R. en la vida del poeta. Sus dos etapas. Lo que yo he escrito del [sic] y lo que le he aconsejado. Su marcha a Madrid. 'Epistolario de un poeta bohemio' ". El "tercer paréntesis" lo dedica Sijé a esbozar unos apuntes del valor del epistolario, y de cómo éste posee un gran interés psicológico. Concluye con un "Final" en el que literalmente deja escrito lo siguiente: "Miguel Hernández, poeta esperanza. Saludo y recuerdo lírico. Aliento".

Aparte de la célebre "Elegía", el poeta dedicó a su amigo el poema "Insomnio", publicado en el número 2 de Destellos del 30 de noviembre de 1930, y "A ti, Ramón Sijé", en la carta que le remitió el 17 de marzo de 1932 desde Madrid.

José Antonio Sáez Fernández ${ }^{77}$ defiende la influencia que ejerció en la obra teatral Los hijos de la piedra (1935), de Miguel Hernández, el contenido del artículo de Sijé "Sobre un futuro teatro español. Meditaciones de Fuenteovejuna", publicado en el rotativo Diario de Alicante el 19 de noviembre de 1931. La propuesta sijeniana era realizar

un teatro nuestro, a la vez, íntimo, de inquietud y espiritualidad, y de todos. Que sea como un gran caracol que recoja las inquietudes todas, de los hombres y de los pueblos unidos en eterna hermandad de trabajadores.

En el mismo artículo de Sijé se defiende un teatro de símbolos, que Hernández llevará hasta sus últimas consecuencias en el auto sacramental Quién te ha visto y quién te ve y sombra de lo que eras (1934). Precisamente, Sijé mediará con Bergamín para que éste publique en su revista, en los números de julio, agosto y septiembre de 1934, el citado auto, escrito a finales del año anterior. Se realizó una edición exenta de 250 ejemplares, que le reportaron al poeta 200 pesetas. Bergamín, en entrevista a Marie Chevallier en diciembre de 1969, afirmó que tuvo que ejercer de "censurable censor" y suprimir algunas tiradas, unos versos, por fascistas. De todos modos, y sin que ello signifique poner en duda esas declaraciones del director de Cruz y Raya, no tenemos constancia de

\footnotetext{
77 “Sobre la posible influencia de un texto de Ramón Sijé en la concepción teatral de Miguel Hernández", Canfali Vega Baja (miércoles, 18-XI-1981), p. 10.
} 
ello, además de lo relativo que resulta calificar a alguien de filofascista según la particular ideología de cada uno. Vemos que no sólo Gecé propendía a llamar fascista a cualquiera que no siguiera la ortodoxia partidista correspondiente.

En este sentido, el esbozo del auto El Amante de su muerte, de Sijé, le permite a Jesucristo Riquelme ${ }^{78}$ afirmar que el ensayista también se dejará notar de nuevo detrás del auto sacramental hernandiano, especialmente desde los puntos de vista temático, ideológico y argumentativo.

En cuanto a textos de Miguel Hernández, en el archivo de Ramón Sijé se conservan los originales mecanoscritos, con añadidos de Sijé, de los poemas "El Silbo de afirmación en la aldea", este último con correcciones manuscritas de Sijé, y "EL TRINO-por la vanidad". Ambos poemas fueron publicados en la revista El Gallo Crisis, ${ }^{79}$ dirigida por el entrañable amigo del poeta.

También se conservan los originales mecanografiados de ocho poemas hernandianos, todos ellos publicados entre febrero y junio de 1930 en la prensa local oriolana: "Soneto", "Fragmento huertano" [fragmento de "Al verla muerta..."], "El alma de la huerta", "A la señorita...", "Postrer sueño", "Es tu boca...", "Ancianidad" y "Ofrenda". En cuanto a prosa, se conservan los mecanoscritos de "Yo. La madre mía" 80 y las escenas IV y V, fragmento "Gallo", de El torero más valiente. En el capítulo de prosa, existe también un recorte del diario murciano La Verdad, de fecha 28 de noviembre de 1932, con el texto hernandiano "Camposanto".

Hemos podido consultar asimismo un cuaderno de 24 páginas con dieciséis poemas, mecanoscritos, que lleva por título "Miguel Hernández. Teatro y prosa. 1934-1937", aunque, a pesar del epígrafe, hay copiados poemas de 1930, 1931, 1932 y 1941-1942.

En el archivo de Ramón Sijé el apartado de epistolario comprende 20 cartas y tarjetas postales de Miguel Hernández dirigidas a Sijé o a la familia de éste, fechadas desde el 12 de diciembre de 1931 hasta el 21 de diciembre de 1939: 12-XII-1931, 11-I-1932, 22-I-1932, h. primeros de 1932, 6-III-1932, 17-III1932 (en las obras completas no se incluyen tres líneas situadas al final de la

\footnotetext{
78 “El pensamiento influyente de Ramón Sijé: utopía y ucronía como alternativas de la realidad republicana", Empireuma (Orihuela), 16 (otoño 1990), s. p.

79 3-4 (San Juan de Otoño de 1934, p.1) y n. ${ }^{\circ}$ 5-6 (Sto. Tomás de la Primavera-Pascua de Pentecostés 1935, pp. 25-30).

${ }^{80}$ Fechado en julio de 1932 y publicado en el único número de la revista El Clamor de la Verdad, en octubre de ese año.
} 
carta, y en el segundo verso del poema incluido, el titulado "A ti, Ramón Sijé", tampoco se transcribe una nota manuscrita del poeta), 22-III-1932, 23-III- 1932, 15-IV-1932, 5-V-1932, 17-V-1932 (muchas variantes), principios de enero de 1936 (mal datada en las obras completas hernandianas, donde se indica la fecha de la contestación por la familia de Sijé, 14 de enero, como fecha de la carta. El matasellos de Madrid es del 30 de diciembre de 1935, y a Orihuela llega al día siguiente), 17-I-1936, 27-I-1936 (en las obras completas figura como fecha el 19 de enero, y en el original se puede advertir con claridad la fecha escrita a mano: "Madrid 27 enero 1936", con matasellos de recepción en Orihuela del 29 de enero), 22-IX-1938 (en las obras completas falta la primera

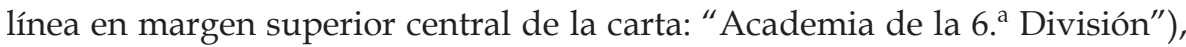
27-II-1939, abril de 1939, 30-V-1939 y 21-XII-1939.

En doce cartas y tarjetas postales: 11-I-1932, 22-I-1932, 6-III-1932, 17III-1932, 22-III-1932, 15-IV-1932, 17-V-1932, 14-I-1936 (fecha errónea en Obra completa), ${ }^{81}$ 17-I-1936, 22-IX-1938, 27-II-1939 y 30-V-1939), se advierten variantes relevantes con relación a las publicadas en las obras completas del poeta y en otros lugares. Dichas variantes tendrán que ser tenidas en cuenta cuando se editen las anunciadas obras completas de Miguel Hernández. Los editores de Obra completa, ya citada y publicada en 1992, no consultaron los originales conservados en este archivo. Además, ha aparecido una carta de Miguel Hernández, manuscrita y firmada, sin fecha, pero de hacia 1932, de dos hojas, supuestamente dirigida a Sijé, en la que, aparte de dos poemas de Góngora ("Vana Rosa" y "Al sepulcro de Dominico Greco, excelente pintor"), al final del último poema, el poeta le dice a su amigo que si no estuviera quemado, como consecuencia de una excursión el día anterior a la Cruz de la Muela, él mismo le llevaría la carta. Esta nota-carta resulta de interés, porque existe un poema atribuido a Hernández con el tema de la fugacidad de la vida como principal argumento. Este poema apócrifo, escrito según Jesucristo Riquelme ${ }^{82}$ en Orihuela hacia 1932, lleva por título “¡Pobre flor!”, y recoge la tradición áurea del contraste vida / muerte y el tema de la fugacidad de la vida.

\footnotetext{
${ }^{81}$ Obra completa. Poesía y Teatro, prosas, correspondencia, tomos I y II, edición crítica de Agustín Sánchez Vidal y José Carlos Rovira, con la colaboración de Carmen Alemany, Madrid, Espasa Calpe, 1992.

${ }^{82}$ M. Hernández, Antología comentada (II, Prosa), edición de Jesucristo Riquelme, Madrid, Ediciones de la Torre, 2002, p. 347.
} 
También se conserva una carta manuscrita inédita, de una hoja escrita por ambas caras, sin fechar pero de hacia el primer trimestre de 1932, de Augusto Pescador, con apostilla de Juan Bellod, en la que el futuro maestro de filósofos en Bolivia y Chile expresa a Sijé su preocupación, y la de los paisanos residentes en Madrid, por la situación, ya insostenible, de Miguel Hernández, y le pide que agilice las gestiones encaminadas a conseguir una beca de la Diputación de Alicante:

A Miguel no le ha gustado Madrid y es lógico pues está en una casa en la que no está nunca solo y tampoco con la compañía que requiere su espíritu, además siempre sin una peseta y desorientado en toda clase de cuestiones intelectuales, no ha encontrado aún lo que le convenía o lo que esperaba y que existe en Madrid. Por tanto yo creo que si Miguel no recibe la pensión que le prometía Albornoz, en cuyo caso ya se podría instalar más confortablemente y mucho más adecuadamente para pensar escribir, etc., Miguel no podrá, aunque consiguiera pagar la casa, estar aquí mucho tiempo.

El espacio dedicado a la situación del poeta es de una cara de la cuartilla, así que con ello podemos calibrar la preocupación que generó esta situación, ciertamente angustiosa para el poeta oriolano, en sus amigos residentes en Madrid.

De otro lado, también ha aparecido un borrador, con membrete de Voluntad, sin datar, con grafía de Sijé, de dos hojas, de un escrito dirigido al Ayuntamiento de Orihuela, en el que se solicita una beca para que Miguel Hernández pueda estudiar en Madrid. Este borrador fue publicado en 1987 por José Muñoz Garrigós ${ }^{83}$ en su mencionado libro. Entresacamos algunos interesantes fragmentos de este documento, escasamente difundido:

Marchando a Madrid, para lograr su plena preparación y depuración estéticas, el poeta oriolano Miguel Hernández y siendo escasísimos sus medios económicos Solicitamos, en nombre de todas las clases sociales de Orihuela, una modesta pensión - pues bien sabemos que en estos tiempos difíciles sólo a eso se puede aspirar - , que le sirva de ayuda en la vida de estudio y trabajo de Madrid.

Después de mencionar las críticas elogiosas de Ernesto Giménez Caballero y de Francisco Martínez Corbalán, el escrito continúa del siguiente modo:

${ }^{83}$ Op. cit., pp. 105-106, n. ${ }^{\circ} 15$. 
Únase a esos laudatorios juicios el que Miguel Hernández haya sido hasta hace poco un obrero manual, lo que nos hace esperar la concesión de lo solicitado por nosotros, pues la República de trabajadores española debe proteger y levantar $-\mathrm{y}$ así lo han proclamado algunos de sus hombres más representativos - al que vale, salga de donde salga. Ocasión se presenta, ahora, a este excelentísimo Ayuntamiento, para cumplir un fuerte imperativo de la democracia republicana: elevación de un obrero a la sagrada categoría de gran poeta.

Eutimio Martín ${ }^{84}$ reconoce, eso sí, que Sijé consiguió que el Consistorio oriolano, en sesión del 3 de marzo de 1932, haga constar en acta lo siguiente:

(...) pide el Sr. Serna que el Ayuntamiento, dentro de sus posibilidades, contribuya con alguna cantidad mensual a la estancia en Madrid de Miguel Hernández Gilabert, humilde hijo de Orihuela, que sin medios de fortuna se ha lanzado en busca de la ilustración y conocimientos necesarios para alcanzar sus naturales dotes de poeta, en la seguridad, dice, de que con ello contribuirá el Ayuntamiento al engrandecimiento de Orihuela, que subirá tanto más cuanto más suban sus hijos; acordándose, en vista de la propuesta, y por unanimidad, señalarle una pensión de cincuenta pesetas mensuales con cargo a imprevistos.

Desgraciadamente, según el propio Martín comenta, el poeta sólo cobró la primera mensualidad, y éste se queja en carta del 7 de junio de ese mismo año al alcalde.

Además de estos importantes materiales, también se conservan dos cartas de Raimundo de los Reyes, responsable de Ediciones Sudeste, editorial adscrita al diario murciano La Verdad. En las cartas, con membrete ambas de la revista literaria Sudeste, fechadas el 28 de junio de 1932 y el 25 de agosto del mismo año, y dirigidas a Ramón Sijé, con quien mantenía una cordial amistad, se habla de la edición del futuro Perito en lunas, a propuesta de Sijé. Concretamente, en la fechada el 28 de junio de 1932, De los Reyes acusa recibo de una anterior de Sijé en la que le anuncia la promesa de "unos buenos versos". El escritor murciano afirma que conoce a Miguel Hernández "Por referencias de Ballesteros y por la Gaceta". En cuanto a la posibilidad de editar al nuevo poeta oriolano, De los Reyes le confiesa a Sijé que

84 "Miguel Hernández: el ejercicio de la literatura como promoción social", en Miguel Hernández: Tradiciones y Vanguardias, op. cit., p. 46. 
Editorialmente no puedo responder a Vd. Mi gusto, desde luego sería editar al Sr. Hernández un libro; pero me coje [sic] Vd. aun [sic] sin repartir ni hacer la oferta y difusión del de Oliver [Tiempo Cenital], editado en circunstancias verdaderamente audaces.

Después de explicar esas causas, de los Reyes ofrece un poco de optimismo:

Sin embargo, de poder salvar cuanto materialmente se empleó en la empresa, pienso repetir, sí señor; de los obstinados es la victoria a veces - las más de las veces - y por esto no ha de quedar ahora. ¿No habría manera de que conociéramos esas poesías?

En la otra carta de Raimundo De los Reyes, del 25 de agosto del mismo año de 1932, comenta a Sijé que todavía no puede adelantarle nada concerniente al libro de Hernández, pero sí que

Sólo le anticipo que lo haremos este otoño, época que me parece la más adecuada para el éxito de estas publicaciones, y no ahora con todo el mundo ausente y la prensa, en el estado en que usted sabe que está. La Verdad no ignorará usted que ha sido clausurada como así también el taller de impresos. De manera que por tanta circunstancia que no escapan a su buen juicio, ha sido imposible que nos ocupemos del libro que tantos deseos tengo de editar.

También existe otro importante documento, con dos versiones manuscritas, que lleva por título “ '...Y los ciegos ven'... Lo barroco, como cosa biológica, en Perito en lunas de M. Hernández". La segunda de ellas complementa a la primera. Que sepamos, no han sido publicadas. Cuatro puntos integran este borrador o guión de un artículo o conferencia, que bien podría ser la citada anteriormente, "Conferencia Ridícula”, pronunciada en la Universidad Popular de Cartagena el 28 de enero de 1933. En relación a este acto celebrado en Cartagena, en el archivo de Sijé se halla una invitación de la FUE (Federación Universitaria Escolar)-Universidad Popular [de Cartagena] de ese día, 28 de enero de 1933, en donde se anuncia la "Conferencia Ridícula" a cargo de Ramón Sijé y "Explicación comentada del cuaderno de poesía Perito en lunas de Miguel Hernández", así como explicación de "ELEGÍA MEDIA-del toro" con ayuda de un cartelón de Rafael González, autor del retrato del poeta oriolano inserto en su mencionado primer poemario. Los cinco pilares sobre los que se sustenta el guión de Sijé aludido anteriormente son: 1.- 'Goethe y 
su absoluta'; 2.- 'Lo barroco como objectum y como subjectum'; 3.- 'Lección de poesía en el seiscientos'; 4.- 'Nueva lección en los tiempos del novecientos', y 5.- 'Las funciones vitales'. El primero de ellos, 'Goethe y su absoluta', llevaría como apuntes, éstos: Poetas sobre y poetas para. Ficha Baudelaire. Ficha Núñez de Arce. Rebeldía sorda de los anticulturantes, masa, infras. Quid de nuestro tiempo: Rathenau, Stoddart, Ortega. El segundo, 'Lo barroco como objectum y como subjectum', no lleva contenido alguno. El tercero, 'Lección de poesía en el seiscientos', incluye: Antigóngora y Ética y estética de Don Luis. El cuarto, ‘Nueva lección en los tiempos del novecientos', contiene Lenguaje, Símbolo y Metáfora. Y en el quinto y último, 'Las funciones vitales', aparece: inmanencia, coherencia y unidad- y el campamento de la cultura. Poema, ciencia, entraña. Cabe decir que la ficha de Baudelaire (la única conservada), tomada de algunos escritos de Paul Verlaine, es muy interesante por su agudeza, ya que capta la esencia de la poética transmitida por el autor de Las flores del mal. Aquí sólo se aportan algunas notas, que podrán ser expuestas en otro lugar con más espacio.

El 29 de abril de 1933 Sijé y Miguel Hernández intervienen en el Ateneo de Alicante. El título de la conferencia del primero de ellos fue "El sentido de la danza. Desarrollo de un problema barroco en Perito en lunas, de Miguel Hernández Giner". Se conocía su contenido gracias a una reseña informativa del diario alicantino El Luchador del 2 de mayo. Sólo se conserva el guión de los cuatro primeros puntos y el título del quinto. Se trata de un documento de doce cuartillas manuscritas a lápiz. En 1987 Muñoz Garrigós ${ }^{85}$ publicó dicho texto. En relación con Miguel Hernández, este guión es muy importante, ya que, según defiende Muñoz Garrigós ${ }^{86}$ en dicha edición, los versos de poetas franceses le llegan a Miguel Hernández a través de Sijé, además de la palabra entendida como ascesis personal, proceso típicamente sijeniano, es trasvasada a Hernández. Según el mismo crítico, la influencia de Eugenio D`Ors en el poeta se percibe en dos puntos: la división dorsiana de la Historia de la Cultura en "corrientes" y "figuras", así como la definición de lo barroco a partir del "pathos"

\footnotetext{
${ }^{85}$ El sentido de la danza, edición y nota de José Muñoz Garrigós, Murcia, Sucesores de Nogués, 1987.

${ }^{86}$ Ibidem, p. 5.
} 
y "logos". Para Sijé, lo barroco se identifica con el "logos", no con el "pathos", teoría central de su ensayo sobre el romanticismo. Además, Miguel Hernández puso como primer título de su auto sacramental La danzarina bíblica.

Por su parte, el poeta explicó "ELEGÍA MEDIA-del toro" con un cartelón de Francisco de Díe. El 28 de julio se repitió el acto en Cartagena, según Sáez Fernández, ${ }^{87}$ con la presencia de Sijé.

Muñoz Garrigós, ${ }^{88}$ en un tan interesante como poco conocido artículo, muestra la diferencia principal entre Miguel Hernández y Ramón Sijé a la hora de componer su obra: el primero, arranca siempre de algo que perciben los sentidos y a partir de ahí construye su propia voz poética. Sijé, por el contrario, toma la idea, abstrae los datos sensoriales y toma como eje el concepto. Sin embargo, ello no tiene ninguna relevancia, ya que el camino tomado por Sijé era el del ensayo, como hemos visto anteriormente, que requiere de una metodología distinta a la creación poética.

El 17 de febrero de 1934 Giménez Caballero escribe a su amigo oriolano una misiva con membrete del yugo y las flechas, alude a Primo de Rivera y Bergamín, y sobre Miguel Hernández afirma, socarronamente: “y Hernández? También ya roñosete? No me ha enviado su libro ni nada...".

En una carta deSijé a sus padres desde Madrid, datada el 30 de diciembre de 1934, les informa que "Estuve en el M.[inisterio] de Instrucción Pública, cumpliendo el encargo de Miguel". Desconocemos de qué asunto se trataba.

En otra carta del escultor talaverano Víctor González Gil a Sijé, fechada el 19 de abril de 1935, con membrete del Centro de Artes y Oficios de Talavera de la Reina, el artista castellano-manchego felicita al ensayista por su trabajo sobre el golpe de Estado, y menciona a Miguel Hernández, con quien, a tenor de lo que comenta en la carta, ya tenía amistad. De hecho, González Gil se despide anunciándole que saldrá en dirección a Madrid dentro de unos días y que en la capital se encontrará con el poeta.

María Zambrano, ${ }^{89}$ en carta dirigida a Ramón Pérez Álvarez fechada el 11 de febrero de 1979, le informa que, en el mismo momento de la muerte de

\footnotetext{
87 “Ramón Sijé y el matrimonio Antonio Oliver-Carmen Conde (Memoria de una amistad)", Oleza (septiembre 1982), s. p.

88 "Miguel Hernández en el marco geográfico y cultural de Orihuela", Revista del Instituto de Estudios Alicantinos, 22 (septiembre-diciembre 1977), p. 22.

${ }^{89}$ J. Muñoz Garrigós, “El último episodio de la amistad entre Miguel Hernández y Ramón Sijé: la 'Elegía'”, Ínsula, 544 (abril 1992), p. 3.
} 
Sijé, Miguel Hernández lo esperaba en la estación de ferrocarril en Madrid, y la filósofa a ambos aquella tarde navideña..$^{90}$

También hemos encontrado diversos poemas, alguno de ellos ciertamente curioso, dedicados a Miguel Hernández. Entre éstos destacamos "A Miguel Hernández", en hoja manuscrita con la significativa fecha "Murcia, 25-IV-42", del escritor gallego pero afincado en Murcia Dictinio de CastilloElejabeytia. Dicho poema no está incluido en su antología Vuelo hacia dentro, ${ }^{91}$ aunque en ella sí aparece "Aquel Miguel Hernández", 92 de tono distinto a éste que comentamos. El poeta gallego participó por esas fechas, en la primavera de 1942, al mes más o menos de morir Miguel Hernández en un homenaje íntimo en Orihuela, como relató en su día Joaquín Ezcurra. Ramón Pérez Álvarez, amigo del poeta en su juventud y compañero de actividades literarias en la efímera revista Silbo (dos números, mayo y junio de 1936) y de cárcel en el Reformatorio de Adultos de Alicante, escribió sólo tres poemas en su vida, uno de ellos, "Tactos", se encuentra mecanoscrito y con abundantes correcciones a mano, firmado por su autor. Fue recogido en el número monográfico dedicado a Hernández de la revista Batarro en $1992 .{ }^{93}$ El también paisano del universal escritor, José M. ${ }^{a}$ Soto de Leyva, escribió un poema, fechado en julio de 1942 (a escasos cuatro meses de la muerte del poeta), que en el archivo de Ramón Sijé se encuentra mecanoscrito. Fue publicado en la revista alicantina Idealidad en $1980^{94}$ e incluido en su libro Poemas. Existe un manuscrito de cuatro hojas del poema "En busca de Miguel Hernández", de Rafael Duyos. Está dedicado "A Mari-Reme y Salvi, de vuestro tío", fechado en Madrid en agosto de 1969, aunque al final del poema, y después de la firma, aparece otra fecha: "Orihuela 16- Julio-1969".

\footnotetext{
${ }^{90}$ Antes de dicha carta a Pérez Álvarez, la propia Zambrano ya lo había contado en “Presencia de Miguel Hernández" en las páginas VI-VII de El País del 9 de julio de 1978.

${ }^{91}$ Murcia, Editora Regional de Murcia, 1987.

${ }^{92}$ Cit., p. 123.

${ }^{93}$ 8-9-10 (enero-diciembre 1992), p. 30.

${ }^{94} 22$ (agosto-septiembre 1980), s. p.
} 


\section{BIOGRAFÍA}

Alonso, C., "Fascismo, catolicismo y romanticismo en la obra de Ramón Sijé", Camp de l'arpa, 11 (mayo 1974), pp. 29-33.

Ballesteros, J. M. ${ }^{\text {a }}$, Memorias completas de José M. ${ }^{a}$ Ballesteros, Madrid, Héroes, 1979.

Castillo-Elejabeytia, D. de, Vuelo hacia dentro, Murcia, Editora Regional de Murcia, 1987.

Conde, C., Tres inolvidables adolescentes de Orihuela y uno de La Unión, Orihuela, Fundación Cultural Miguel Hernández, 2007.

Díez De Revenga, F. J., Revistas murcianas relacionadas con la generación del 27, Murcia, Academia Alfonso X El Sabio, 1979.

El Gallo Crisis, edición facsímil, prólogo y comentarios de José Muñoz Garrigós, Orihuela, Publicaciones del Excmo. Ayuntamiento de Orihuela, 1973.

Fernández Palmeral, R., Simbología secreta de 'La decadencia de la flauta y el reinado de los fantasmas', de Ramón Sijé, estudio e ilustraciones de Ramón Fernández Palmeral, prólogo de José A. Sáez Fernández, Alicante, Editorial Palmeral, 2005.

Galiano Pérez, A. L. (ed.), Ramón Sijé: Luces y sombras, Alicante, Caja de Ahorros de Alicante y Murcia, 1987.

García-Molina Martínez, A., “Oleza a Gabriel Miró. Dos conferencias de los hermanos Sijé", Revista del Instituto de Estudios Alicantinos, 27 (mayo-agosto 1979), pp. 243-258.

Giménez Caballero, E. Memorias de un dictador, Barcelona, Planeta, 1979.

Guillén García, J.-Muñoz Garrigós, J., Antología de Escritores Oriolanos, Orihuela, Publicaciones del Excmo. Ayuntamiento de Orihuela, 1974, pp. 193-207.

Guillén García, J., “Miró y la generación olecense de 1930”, Monteagudo, 65 (1979), pp. 21-26.

Hernández, M., Obra completa. Poesía y Teatro, prosas, correspondencia, tomos I y II, edición crítica de Agustín Sánchez Vidal y José Carlos Rovira, con la colaboración de Carmen Alemany, Madrid, Espasa Calpe, 1992.

Antología comentada (II, Prosa), edición de Jesucristo Riquelme, Madrid, Ediciones de la Torre, 2002.

Isla. Hojas de Arte, Letras y Polémica [1932-1936], edición y prólogo de José M. ${ }^{\text {a Barrera }}$ López, Sevilla, Editorial Renacimiento-Servicio de Publicaciones, Diputación de Cádiz-Centro Cultural de la Generación del 27, 2006.

JiméNeZ, J. R., Ideolojía-II, justificación, glosas y sugerencias de Emilio Ríos, Moguer, Ediciones de la Fundación Juan Ramón Jiménez, 1998, p. 33. 
Martín, E., "Ramón Sijé-Miguel Hernández: una relación mitificada”, en Miguel Hernández, cincuenta años después. Actas del I Congreso Internacional, Alicante, Comisión del Homenaje a Miguel Hernández, 1993, I, pp. 43-58.

, "Miguel Hernández: el ejercicio de la literatura como promoción social", en Serge Salaün-Javier Pérez Bazo (eds.), Miguel Hernández: Tradiciones y Vanguardias, Alicante, Instituto de Cultura Juan Gil-Albert, 1996, pp. 43-49.

MARrAST, R., "Ramón Sijé y el romanticismo o el arte del galimatías reaccionario", en Miguel Hernández: Tradiciones y Vanguardias, op. cit., pp. 51-57.

Muñoz Garrigós, J., El Gallo Crisis, memoria de licenciatura dirigida por Mariano Baquero Goyanes, Murcia, Universidad de Murcia, 1967.

, "El Gallo Crisis", Revista del Instituto de Estudios Alicantinos, 4 (agosto 1970), pp. [19]-47.

--------, "El Gallo Crisis" [Conclusión], Revista del Instituto de Estudios Alicantinos, 5 (enero 1971), pp. [21]-39.

--------, "El Gallo Crisis", Boletín de la Asociación Europea de Profesores de Español (Madrid), 9 (octubre 1973), pp. 107-111.

---------, "Miguel Hernández en el marco geográfico y cultural de Orihuela", Revista del Instituto de Estudios Alicantinos, 22 (septiembre-diciembre 1977), pp. [7]-24.

---------, “La opinión de Ramón Sijé sobre Francisco Salzillo (Notas de asalto a dos estéticas levantinas)", Monteagudo, 83 (1983), pp. 5-16.

, “Miguel Hernández desde la lengua (Primera página de unas notas a Perito en lunas, en su cincuentenario)", Revista del Instituto de Estudios Alicantinos, 40 (septiembre-diciembre 1983), pp. [103]-113.

, "El final de una polémica (Documento inédito de Ramón Sijé)", Anales de la Universidad de Murcia, XLII, 1-2 (1983-1984), pp. [211]-217.

---------, Vida y obra de Ramón Sijé, prólogo de Jesús Manuel Alda Tesán, MurciaOrihuela, Secretariado de Publicaciones de la Universidad de Murcia-Caja Rural Central de Orihuela, 1987.

, "El itinerario andaluz de Ramón Sijé, según las cartas a su familia", en Homenaje a Justo García Morales. Miscelánea de estudios con motivo de su jubilación, Madrid, Asociación Española de Archiveros, Bibliotecarios, Musicólogos y Documentalistas (ANABAD), 1987, pp. [821]-839.

, “Miguel Hernández y Ramón Sijé”, en F.J. Díez de Revenga-M. De Paco (eds.), Estudios sobre Miguel Hernández, Murcia, Universidad de Murcia, 1992, pp. [275]- 286. 
----------, “El último episodio de la amistad entre Miguel Hernández y Ramón Sijé. 'La Elegía'”, Ínsula, 544 (abril 1992), pp. 3-4.

, “Nota introductoria sobre ‘Murió Ramón Sijé!' ”, Batarro (Albox), 8-9-10 (enero-diciembre 1992), pp. 114-118.

, “El padre Granada visto por Ramón Sijé: El sermón del día de la Asunción”, en Fray Luis de Granada, su obra y su tiempo. Actas del Congreso Internacional, Granada, 27-30 setiembre 1988, Fray Antonio García del Moral / Fray Urbano Alonso del Campo (eds.), Granada, Universidad de Granada, 1993, vol.II, pp.[379]-385.

Penalva, J. J., "Tres poetas del 36 en El Gallo Crisis: Félix Ros, Luis Felipe Vivanco y Luis Rosales", Alquibla (Orihuela), 8 (2002), pp. 553-572.

Peral Baeza, G., "Miguel Hernández y el ensayo de Ramón Sijé sobre el romanticismo”, El Eco Hernandiano (Orihuela), 9 (primavera 2006), pp. 2-10.

Poveda, J., Vida, pasión y muerte de un poeta: Miguel Hernández, México, Ediciones Oasis, 1975.

, “Amistad con Ramón Sijé", Batarro (Albox), 2 (enero-abril 1990), pp. 21-22.

Quílez y SANZ, J. M. ', Pasión y compasión en el concepto de propiedad, Orihuela, Biblioteca de El Gallo Crisis, n. ${ }^{\circ} 1$, 'El Perfume Intenso', 1934, 8 pp. Impreso en Editorial La Verdad. S.A., de Murcia.

Ramos, V., "Ramón Sijé”, Información (Alicante) (2-IV-1957).

--------, Miguel Hernández, Madrid, Gredos, 1973.

-------, “Oleza a Gabriel Miró”, Revista de Moros y Cristianos (Orihuela), 1980, s.p.

ReIg Sempere, A.M., La generación del 30 en Orihuela, Alicante, Instituto de Estudios Alicantinos, 1981.

Riquelme, J., “Causas de una producción artística: Quien te ha visto y quien te ve, auto sacramental de M. Hernández", Revista del Instituto Estudios Alicantinos, 37 (septiembre-diciembre 1982), pp. [175]-191.

---------, “El pensamiento influyente de Ramón Sijé: utopía y ucronía como alternativas de la realidad republicana”, Empireuma (Orihuela), 16 (otoño 1990), s. p.

Rodríguez CÁnovas, J., Antonio Oliver Belmás y la Universidad Popular de Cartagena, Cartagena, Imprenta Molegar, 1971, pp. 43-45.

SÁEz FERNÁNDEZ, J.A., “Sobre la posible influencia de un texto de Ramón Sijé en la concepción teatral de Miguel Hernández", Canfali Vega Baja (Orihuela) (18-XI-1981), p. 10.

---------, "Ramón Sijé y el matrimonio Antonio Oliver-Carmen Conde (Memoria de una amistad)", Oleza (Orihuela) (septiembre 1982), s.p. 
----------, “Desagravio y recuerdo: gestación de un magno homenaje oriolano a la memoria de Gabriel Miró", Canfali Vega Baja (Orihuela) (6-X-1982), pp. 8-9.

, "Ramón Sijé y José Bergamín: amistad y discrepancias", Anales del Colegio Universitario de Almería. Letras (Almería), V (1983-1984), pp. 7-13.

------, (ed.), Textos sobre Ramón Sijé, Almería, Imprenta Cervantes, 1985.

SÁnchez Vidal, A., Miguel Hernández en la encrucijada, Madrid, Cuadernos para el Diálogo, 1976.

SIJÉ, R., La decadencia de la flauta y el reinado de los fantasmas. Ensayo sobre el romanticismo histórico en España (1830-Bécquer), prólogo de Manuel Martínez Galiano, Alicante, Instituto de Estudios Alicantinos, 1973.

---------, El sentido de la danza, edición y nota de José Muñoz Garrigós, Murcia, Sucesores de Nogués, 1987.

--------, Oleza, pasional natividad estética de Gabriel Miró, edición y estudio preliminar a cargo de José Antonio Sáez Fernández, Albox, Batarro, 1990.

Soto de Leyva, J. M. ${ }^{\text {a }}$ Poemas, preliminar de Vicente Ramos, Orihuela, J. M. ${ }^{\text {a }}$ Soto, 1989.

Zardoya, C., Miguel Hernández (1910-1942)-Vida y obra-Bibliografía-Antología, New York, Hispanic Institute in the United States, 1955. 